\title{
Kinase-mediated regulation of common transcription factors accounts for the bone-protective effects of sex steroids
}

\author{
Stavroula Kousteni, ${ }^{1}$ Li Han, ${ }^{1}$ Jin-Ran Chen, ${ }^{1}$ Maria Almeida, ${ }^{1}$ Lilian I. Plotkin, ${ }^{1}$ \\ Teresita Bellido, ${ }^{1}$ and Stavros C. Manolagas ${ }^{1,2}$
}

${ }^{1}$ Division of Endocrinology and Metabolism, Center for Osteoporosis and Metabolic Bone Diseases, University of Arkansas for Medical Sciences, and

${ }^{2}$ Central Arkansas Veterans Health Care System, Little Rock, Arkansas, USA

It has been found that 4-estren-3 $\alpha, 17 \beta$-diol, a synthetic ligand for the estrogen receptor (ER) or androgen receptor (AR), which does not affect classical transcription, reverses bone loss in ovariectomized females or orchidectomized males without affecting the uterus or seminal vesicles, demonstrating that the classical genotropic actions of sex steroid receptors are dispensable for their bone-protective effects, but indispensable for their effects on reproductive organs. We have now investigated the mechanism of action of this compound. We report that, identically to $17 \beta$-estradiol or dihydrotestosterone, but differently from raloxifene, estren alters the activity of Elk-1, CCAAT enhancer binding protein- $\beta$ $(C / E B P \beta)$, and cyclic adenosine monophosphate-response element binding protein (CREB), or c-Jun/ c-Fos by an extranuclear action of the ER or AR, resulting in activation of the Src/Shc/ERK pathway or downregulation of JNK, respectively. All of these effects are non-sex specific, require only the ligandbinding domain of the receptor, and are indispensable for the antiapoptotic action of these ligands on osteoblastic and HeLa cells. Moreover, administration of $17 \beta$-estradiol or 4-estren-3 $\alpha, 17 \beta$-diol to ovariectomized mice induces phosphorylation of ERKs, Elk-1, and C/EBP $\beta$, downregulates c-Jun, and upregulates the expression of egr-1, an ERK/SRE target gene. Kinase-initiated regulation of commonly used transcription factors offers a molecular explanation for the profound skeletal effects of sex steroid receptor ligands, including synthetic ones that are devoid of classical transcriptional activity.

J. Clin. Invest. 111:1651-1664 (2003). doi:10.1172/JCI200317261.

Received for publication October 29, 2002, and accepted in revised form March 11, 2003.

Address correspondence to: Stavros C. Manolagas, 4301 West Markham, Slot 587, Little Rock, Arkansas 72205, USA.

Phone: (501) 686-5130; Fax: (501) 686-8148;

E-mail: manolagasstavros@uams.edu.

Portions of this work were presented in abstract form at the 23rd Annual Meeting of the American Society for Bone and Mineral

Research in Phoenix, Arizona, USA, on October 14, 2001 (2001. J. Bone Miner. Res. 16:S159; 2001. J. Bone Min. Res. 16:S415) and at the 24th Annual Meeting of the American Society for Bone and Mineral

Research in San Antonio, Texas, USA, on September 24, 2002 (2002.

J. Bone Miner. Res. 17:S169).

Conflict of interest: Stavroula Kousteni, Teresita Bellido, and Stavros

C. Manolagas own shares in a biotechnology company, Anabonix Inc., which was founded by S.C. Manolagas. This company has a licensing agreement with the University of Arkansas for Medical Sciences to develop and commercialize anabolic drugs for the treatment of osteoporosis, including the prototypic ligands described in this manuscript.

Nonstandard abbreviations used: estrogen receptor (ER); androgen receptor (AR); estrogen response element (ERE); androgen response element (ARE); extracellular signal-regulated kinase (ERK); dihydrotestosterone (DHT); $17 \beta$-estradiol ( $\left.\mathrm{E}_{2}\right)$; CCAAT enhancer binding protein- $\beta(\mathrm{C} / \mathrm{EBP} \beta)$; early growth response -1 protein gene (egr-1); serum response element (SRE); secreted alkaline phosphatase (SEAP); dominant negative (dn); Src mutant lacking kinase activity $\left(\mathrm{Src} \mathrm{K} \mathrm{K}^{-}\right.$; $\mathrm{ER} \alpha$ ligand-binding domain (E); E localized to the plasma membrane (E-Mem); E localized to the nucleus (E-Nuc); cyclic adenosine monophosphate-response element binding protein; nuclear red fluorescent protein (nRFP); ovariectomized (ovx); complement 3 (C3); ribosomal S6 kinase (Rsk2); cyclic adenosine monophosphate response element-binding protein (CREB); green fluorescent protein fused to wild-type ERK2 (GFP-ERK2); selective estrogen receptor modulator (SERM); bone mineral density (BMD); double estrogen receptor knockout (DERKO); activators of nongenotropic estrogenlike signaling (ANGELS).

\section{Introduction}

Estrogens and androgens exert regulatory influences on a wide variety of biological processes by signaling through highly specialized proteins belonging to the superfamily of nuclear receptors: the estrogen receptors (ERs) $\alpha$ and $\beta$ and the androgen receptor (AR) (1-3). Binding of the hormone to the receptor causes homo- or heterodimerization of the protein and changes its conformation in such a way that it allows the dimer to interact with several coactivator proteins. The receptor-coactivator(s) complex attaches to specific DNA response elements (estrogen response elements [EREs] and androgen response elements [AREs]) and the basal transcription machinery, causing histone acetylation, decondensation of the chromatin, and initiation of transcription. Estrogens and androgens also regulate the transcription of genes that do not contain EREs or AREs. In this case the ligandactivated receptors form protein-protein complexes with other transcription factors, thus preventing them from interacting with their target gene promoters (4).

Nonetheless, numerous effects of estrogens and androgens cannot be explained by the established models of transcriptional regulation resulting from cis- or trans-interactions of their classical nuclear receptor proteins with DNA. To distinguish them from the classical, 
or so-called genotropic mechanisms, such effects have been attributed collectively to nongenotropic actions a term applied to a large range of effects varying from physicochemical or ionic changes to receptor-independent actions or to actions mediated by putative membrane receptors (5-8). The relationship of nongenotropic actions to the better-known effects of sex steroids on transcription remains largely unknown. Moreover, until very recently, there had been no evidence that nongenotropic actions of sex steroids are of biological relevance in vivo.

One of the best-documented nongenotropic actions of estrogens in a variety of cell types, including bone, endothelial, and neuronal cells, is the activation of the MAPKs, serine-threonine kinases that transduce chemical and physical signals from the cell surface to the nucleus, thereby controlling proliferation, differentiation, and survival (9). MAPKs might alter cellular functions by modifying the activity of proteins independent of any transcriptional changes or through changes in gene transcription resulting from the phosphorylation of transcription factors. The three better-characterized subfamilies of MAPKs are the extracellular signal-regulated kinases (ERKs), the JNKs, and the p38 kinases.

We had earlier elucidated that estrogens and androgens attenuate the apoptosis of osteoblasts/osteocytes by rapidly activating the Src/Shc/ERK signaling pathway (10). This effect requires only the ligand-binding domain of the receptor, and unlike the classical genotropic action of the receptor protein, it is eliminated by nuclear targeting. Unexpectedly, ER $\alpha, \mathrm{ER} \beta$, or AR mediate this effect with similar efficiency, irrespective of whether the ligand is an estrogen or an androgen. Moreover, this nongenotropic effect can be dissociated from the genotropic actions of the receptors with synthetic ligands. More recently, we have used such ligands to show that sex steroids protect the adult murine skeleton through a fundamentally distinct mechanism of receptor action different from that used to preserve the mass and function of reproductive organs (11). Specifically, we have found that whereas the classical genotropic action of sex steroid receptors is essential for their effects on reproductive tissues, this action is dispensable for their bone-protective effects. Moreover, whereas sex steroids preserve bone mass, 4-estren- $3 \alpha, 17 \beta$-diol, a synthetic prototypic ligand referred to hereafter as estren, faithfully reproduces their nongenotropic effects without affecting classical transcription, increases bone mass in ovariectomized females above the level of the estrogen replete state, and is at least as effective as dihydrotestosterone (DHT) in orchidectomized males, without affecting reproductive organs in either sex.

In the studies described here, we have used estren, $17 \beta$ estradiol ( $\mathrm{E}_{2}$ ), DHT, and 1,3,5-tris(4-hydroxylphenyl)-4propylpyrazole, referred to hereafter as pyrazole, a compound that reproduces the genotropic actions of $E_{2}$. Using these compounds, we have investigated whether nongenotropic activation of kinases by ligands of the ER or AR influences transcription and whether transcrip- tion is required for the antiapoptotic effect of sex steroids. We show that activation of the Src/Shc/ERK pathway or downregulation of JNK by sex steroids through an extranuclear action mediated by the ligandbinding domain of their receptors leads to potent downstream modulation of the activity of Elk-1/serum response element (Elk-1/SRE) and AP-1, respectively. Both these effects can be transmitted by either the ER $\alpha$ or the AR in an interchangeable ligand-receptor interaction manner, in the sense that ER $\alpha$ or AR can mediate them with similar efficiency, irrespective of whether the ligand is $\mathrm{E}_{2}$ or DHT. Besides transcription-dependent events, selective activation of cytoplasmic kinases and downstream transcription-independent events are also required for the antiapoptotic effects of sex steroids on osteoblasts and HeLa cells. Furthermore, and consistent with the ability of estren to dissociate the skeletal from the reproductive actions of these receptors in vivo, we demonstrate that this novel synthetic analogue, but not pyrazole, faithfully reproduces the activating and repressing actions of sex steroids on transcription factors through the ER or the AR in vitro. Moreover, estren, like $\mathrm{E}_{2}$, induces phosphorylation of ERKs, Elk-1, and CCAAT enhancer binding protein- $\beta$ (C/EBP $\beta$ ), downregulates c-Jun, and upregulates the expression of the early growth response-1 protein gene (egr-1), an ERK/SRE target gene, in vivo.

\section{Methods}

Chemicals. DHT, raloxifene (LY139481 HCl), etoposide, actinomycin D, cycloheximide, wortmannin, and PMA were purchased from Sigma-Aldrich (St. Louis, Missouri, USA). Recombinant human IL-1 $\beta$ (specific activity $=1.8 \times 10^{4} \mathrm{U} / \mathrm{mg}$ ) was donated by the Biological Resources Branch, National Cancer Institute Preclinical Repository (Rockville, Maryland, USA). Recombinant murine TNF- $\alpha$ (specific activity $=5 \times 10^{7} \mathrm{U} / \mathrm{mg}$ ) was purchased from Genzyme Pharmaceuticals (Cambridge, Massachusetts, USA). Estren was purchased from Steraloids Inc. (Newport, Rhode Island, USA), and pyrazole was kindly provided by John A. Katzenellenbogen (University of Illinois at Urbana, Urbana, Illinois, USA) (12, 13). Slow-release pellets containing $E_{2}$, estren, or raloxifene were purchased from Innovative Research of America (Sarasota, Florida, USA).

Cell cultures. Osteoblastic cells were obtained from neonatal murine calvaria and cultured as described previously (14). Osteocytic MLO-Y4 cells, osteoblastic OB-6 cells, and HeLa cells were cultured in phenol red-free $\alpha M E M$ as described previously (15-17). Osteoclasts were formed in ex vivo cultures of murine bone marrow aspirates containing $30 \mathrm{ng} / \mathrm{ml} \mathrm{M}$-CSF and soluble RANK ligand, as described previously (18).

Plasmids. SRE- and AP-1-SEAP (AP-1-secreted alkaline phosphatase) were purchased from CLONTECH Laboratories Inc. (Palo Alto, California, USA). The IL-6luciferase reporter contains a $1.2-\mathrm{kb}$ fragment of the $5^{\prime}$ flanking region of the IL- 6 gene and has been described previously (17). ElkC, ElkC383/389, dominant negative 
(dn) Elk-1 were obtained from S. Safe (Texas A \& M University, College Station, Texas, USA) (19). GAL4-luc was obtained from M. Karin (University of California, San Diego, San Diego, California, USA) (20). Construction of the human ER $\alpha$ ligand-binding domain (E), E localized to the plasma membrane (E-Mem), and $\mathrm{E}$ localized to the nucleus (E-Nuc) mutants containing the ligandbinding domain of $E R \alpha$ fused to the cyan fluorescent protein, and either a membrane or a nuclear localization sequence, respectively, was previously described (10). Expression and appropriate localization of the constructs inside the cells were confirmed by fluorescent microscopy. The cDNAs for WT Src and SrcK295M (lacking kinase activity; Src K-), WT or She mutants, and dn MEK were provided by W.C. Horne (Yale University, New Haven, Connecticut, USA) (21); K.S. Ravichandrian (University of Virginia, Charlottesville, Virginia, USA) (22); and N.G. Ahn (University of Colorado, Boulder, Colorado, USA) (23), respectively. JNK1 and dn JNK1 were obtained from R.J. Davis (University of Massachusetts, Worcester, Massachusetts, USA) (24). WT and dn ribosomal S6 kinase (Rsk2) and WT and dn AKT were obtained from M.E. Greenberg, Harvard Medical School (Boston, Massachusetts, USA) (25). The dn $\mathrm{Bad}$, in which serines 112,136 , and 155 were mutated to alanine, was provided by X.-M. Zhou (Apoptosis Technology Inc., Cambridge, Massachusetts, USA) (26). The dn cyclic adenosine monophosphate-response element binding protein (CREB) and dn C/EBP $\beta$ were provided by C. Vinson, NIH, Bethesda, Maryland, USA (27). The dn AP-1 (TAM67) was provided by T. Chambers (University of Arkansas for Medical Sciences) (28). The nuclear red fluorescent protein (nRFP) construct was obtained by attaching the SV40 large T-antigen nuclear localization sequence (29) to the amino terminus of the cDNA construct encoding RFP (pDs1Red1-N1; CLONTECH Laboratories Inc.). Green fluorescent protein fused to wild-type ERK2 (GFP-ERK2) was provided by R. Seger, Department of Biological Regulation, The Weizmann Institute of Sciences, Rehovot, Israel (30).

Transient transfections and reporter assays. HeLa cells were transfected with $0.1 \mu \mathrm{g}$ ER $\alpha, 0.2 \mu \mathrm{g}$ of each appropriate reporter construct, or $0.2 \mu \mathrm{g}$ of each dn kinase or transcription factor mutant using Lipofectamine Plus (Invitrogen Corp., Carlsbad, California, USA). To determine SEAP activity, cells were allowed to recover for 24 hours in the presence of $10 \%$ serum and then cultured for additional 24 hours in serum-free conditions to decrease the basal levels of SRE-SEAP activity. Subsequently, they were treated with the indicated steroids for 15 minutes, after which the steroid-containing media were removed, cells washed twice with $1 \%$ BSA in PBS, and fresh media without steroid were added. SEAP or luciferase assays were performed 6 hours later using the Great EscAPe SEAP Chemiluminescence Kit (CLONTECH Laboratories Inc.) or the dual luciferase kit (Promega Corp., Madison, Wisconsin, USA), respectively, according to the manufacturer's instructions. To examine the effect on IL-6 activity, transfected cells were recovered as above, pretreated with IL- $1 \beta(1.6 \mathrm{nM})$ and TNF- $\alpha(0.3 \mathrm{nM})$ or PMA $(160 \mathrm{nM})$ for 24 hours, and then treated with $10^{-8} \mathrm{M}$ of the appropriate compound. IL-6-luciferase activity was determined 24 hours later. SEAP or IL-6-luciferase activities were normalized for Renilla-luciferase activity.

Subcellular localization of ERK2. MLO-Y4 cells were transfected with GFP-ERK2 to allow the visualization of ERK and with nRFP to allow the localization of the cell nuclei. Following transfection, cells were cultured for 48 hours, serum-starved for 40 minutes, and subsequently treated with vehicle (ethanol), $\mathrm{E}_{2}$, estren, or pyrazole at a final concentration of $10^{-7} \mathrm{M}$, or as otherwise indicated, for 5 minutes. Cells were fixed in neutral buffer formalin for 8 minutes. The percentage of cells showing nuclear accumulation of ERK2 was quantified by enumerating those cells exhibiting increased GFP in the nucleus compared with the cytoplasm, using a fluorescence microscope. At least 250 cells from random fields were examined for each experimental condition.

Preparation of bone extracts for Western blot analysis. The fifth lumbar vertebrae (L5) were obtained from each experimental mouse. Vertebrae were thoroughly cleaned to remove the spinal cord and the attached soft tissues, washed once with PBS, and placed in Tris-buffered saline $\mathrm{Na}$ orthovanadate until they were homogenized in lysis buffer $(20 \mathrm{mM}$ Tris- $\mathrm{HCl}, \mathrm{pH} 7.5,150 \mathrm{mM} \mathrm{NaCl}$, $1 \mathrm{mM}$ EDTA, $5 \mu \mathrm{g} / \mathrm{ml}$ leupeptin, $0.14 \mathrm{U} / \mathrm{ml}$ aprotinin, $10 \mathrm{mM} \mathrm{NaF}, 1 \mathrm{mM}$ Na orthovanadate, $1 \mathrm{mM}$ PMSF, $1 \%$ Triton-X 100). Lysates were centrifuged at $15,000 \mathrm{~g}$, for 15 minutes. Five to $30 \mathrm{mg}$ of protein were used for Western blot analysis.

Western blot analysis. The phosphorylation status of ERK-1 and -2, Elk-1, C/EBP $\beta$, CREB, and c-Jun was analyzed by immunoblotting. The Ab's used were as follows: a mouse $\mathrm{mAb}$ recognizing tyrosine phosphorylated ERK-1 and - 2 and a rabbit polyclonal Ab recognizing total ERK-1 and -2; a mouse mAb recognizing serine383 phosphorylated Elk-1 and a rabbit polyclonal $\mathrm{Ab}$ recognizing total Elk-1; a goat polyclonal $\mathrm{Ab}$ recognizing threonine- 217 phosphorylated $\mathrm{C} / \mathrm{EBP} \beta$ and a goat polyclonal $\mathrm{Ab}$ recognizing total $\mathrm{C} / \mathrm{EBP} \beta$; a goat polyclonal $\mathrm{Ab}$ recognizing serine- 133 phosphorylated CREB and a rabbit polyclonal $\mathrm{Ab}$ recognizing total CREB (Santa Cruz Biotechnology Inc., Santa Cruz, California, USA); and a human $m A b$ recognizing serine- 63 and serine-73 phosphorylated c-Jun and a mouse $\mathrm{mAb}$ recognizing total Jun (CLONTECH Laboratories Inc.).

Real-time PCR. Total RNA was extracted using Ultraspec RNA (Biotecx Laboratories, Houston, Texas, USA), and the expression of $\mathrm{C} 3$ and egr-1 mRNA was measured by real-time RT-PCR using the ABI PRISM 7700 Sequence Detector and the TaqMan Universal PCR Master Mix (Applied Biosystems Inc., Foster City, California, USA). The primers and probes were manufactured by Assays-by-Design Service (Applied Biosystems Inc.) and were as follows: $C 3$ probe, $5^{\prime}$-TCTCCATCAAGATTCC-3', forward primer, GGAGCCAGTGGACATCTGAGA, reverse primer, CССТCCTTATCTGAGTTGAATTCCT; egr-1 probe, 

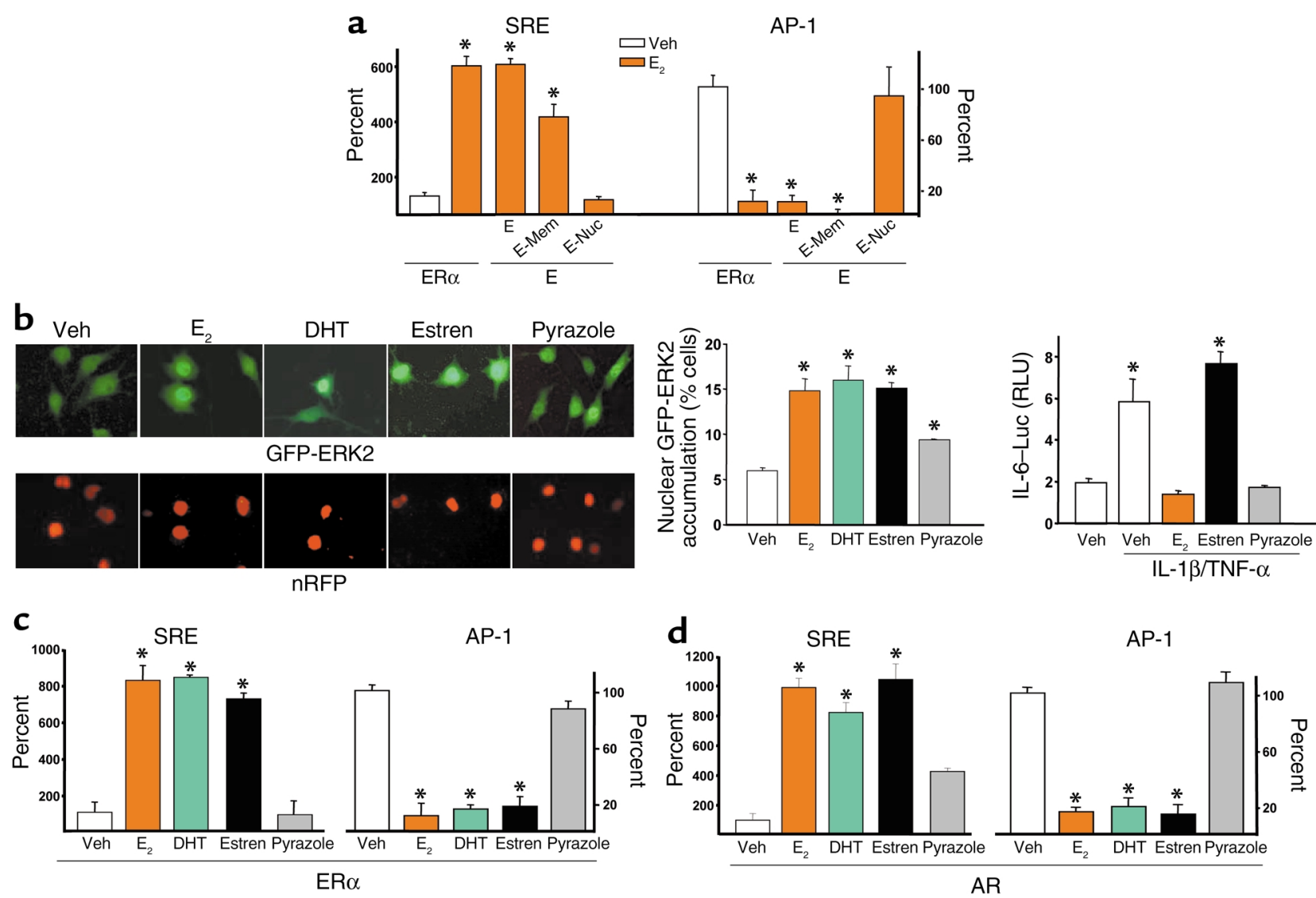

Figure 1

Nongenotropic regulation of cytoplasmic kinases by sex steroids. HeLa cells were transfected with reporter constructs in which SRE or AP-1 drive the expression of SEAP. Aliquots of these cells were then cotransfected with either the full-length ER $\alpha$, or its ligand-binding domain (E), or the $E$ domain fused to a membrane localization sequence (E-Mem) or nuclear localization sequence (E-Nuc) and treated with vehicle $(V e h)$ or $E_{2}\left(10^{-8} \mathrm{M}\right)$ for 15 minutes. The steroid-containing media were removed, the cells were washed twice, and the cultures were continued in fresh medium without $\mathrm{E}_{2}$. Supernatants were collected 6 hours later, and SEAP activity was assayed (a). MLO-Y4 cells transfected with GFP-ERK2 and nRFP were treated for 5 minutes with $10^{-7} \mathrm{M}$ of the indicated compounds, and nuclear accumulation of GFP-ERK2 (left upper panels of b) was quantified as described in Methods and shown in left graph. The expression of nRFP in the nuclei is shown in the left lower panels of $\mathbf{b}$. Regulation of IL- 6 activity by $10^{-8} \mathrm{M} \mathrm{E}_{2}$, estren, or pyrazole is shown in the right graph (b). RLU, relative luciferase units. HeLa cells transfected with the ER $\alpha(\mathbf{c})$ or the AR $(\mathbf{d})$ were exposed to vehicle or $10^{-8} \mathrm{M}$ of the indicated steroids for 15 minutes as described in $\mathbf{a}$, and SEAP activity was assessed 6 hours later. One hundred percent indicates activity in vehicle-treated cells. Bars indicate means \pm SD of triplicate determinations; ${ }^{*} P<0.05$ versus vehicle by ANOVA.

5'-AGGCTCTAAAACCC-3', forward primer, TCTGGGTGGTGCATTGGAA, reverse primer, CGGCCACCAGTCAGTAGGTT.

Quantification of apoptotic cells in vitro. Apoptotic cells were quantified either by trypan blue staining (see Figure $4 \mathrm{~b}$ and Figure $6 \mathrm{a}$ ) or by direct visualization of nuclear morphology in cells cotransfected with nuclear GFP (see Figure 4, $c$ and d, and Figure 6, b and c) as described previously (10) or by measuring caspase-3 activity (see Figure 7, a and c) as described previously (18). In some experiments apoptosis was assayed by monitoring caspase-3 activity in individual cells (see Figure 7b) following transfection into the cells of a vector that contains a caspase-3 sensor protein fused to a yellow fluorescent protein (CLONTECH Laboratories Inc.).

Statistical analysis. The data were analyzed by ANOVA, and the Student-Newman-Kleuss method was used to estimate the level of the significance of differences between means.

\section{Results}

Nongenotropic regulation of SRE- and AP-1-mediated transcription downstream of ERK and JNK kinase modulation. Activation of the ERKs and JNK leads to SRE-dependent and AP-1-dependent transcription, respectively (31, 32). Based on this evidence and our earlier finding that $\mathrm{E}_{2}$, DHT, as well as an estren, but not a pyrazole, activate ERKs in a nongenotropic manner, we searched for the effects of these ligands on SRE- or AP-1-dependent transcription downstream from cytosolic kinases. Exposure to $\mathrm{E}_{2}$ for as little as 15 minutes was sufficient to stimulate SRE-dependent and downregulate AP-1dependent transcriptional activity in HeLa cells (Figure 1a). Effects identical to those obtained in HeLa cells transfected with the full-length ER $\alpha$ were demonstrated in cells transfected with a mutant comprising only the ligand-binding domain (E). In full agreement with our earlier observations on the activation of the 
Src/Shc/ERK signaling pathway and antiapoptosis, E-Mem, but not E-Nuc, preserved the hormonal effects on both SRE and AP-1. ER $\alpha$ and the different E mutants were equally expressed as demonstrated by the similar level of expression of cyan fluorescent protein in cells transfected with each one of the constructs. None of the ER constructs affected basal SRE or AP-1 activity. These results demonstrate that direct receptorDNA interaction is dispensable for the regulation of SRE and AP- 1 activity by $E_{2}$ and that this effect is maintained with membrane but not nuclear localization of the receptor protein.

We have shown previously that estren mimics the nongenotropic effects of $\mathrm{E}_{2}$ without inducing its genotropic actions. Specifically, estren is a potent inducer of ERK activation without stimulating transcription via direct DNA binding on ERE sites (10). Consistent with these earlier observations, estren stimulated nuclear accumulation of the GFP-ERK2 fusion protein in MLO-Y4 osteocytic cells as effectively as $\mathrm{E}_{2}$ or DHT, but did not downregulate IL-1 $\beta /$ TNF- $\alpha$-stimulated IL-6 transcription, an effect resulting from ER interactions with other transcription factors (Figure 1b). On the other hand, pyrazole at $10^{-7} \mathrm{M}$ had only a small effect in inducing GFP-ERK2 nuclear accumulation, whereas it was as effective as $E_{2}$ in inhibiting IL- 6 transcription at $10^{-8} \mathrm{M}$ (Figure $1 \mathrm{~b}$ ), suggesting that pyrazole might not be a pure genotropic agent, but have weak nongenotropic activity as well (10). Stimulation of SRE and downregulation of AP-1 was also demonstrated in ER $\alpha$-transfected HeLa cells treated with DHT or estren, but not pyrazole, indicating that ER-dependent SRE and AP-1 regulation occurs through a nongenotropic mechanism of receptor action (Figure 1c). Importantly, HeLa cells transfected with an empty vector instead of the ER did not exhibit the effects of $\mathrm{E}_{2}$ or DHT, establishing that these phenomena were ER dependent (data not shown). Results identical to those shown with HeLa cells transfected with ER $\alpha$ were obtained using HeLa cells transfected with the AR (Figure 1d). Moreover, either the ER antagonist ICI 182,780 or the AR antagonist flutamide abrogated the effect of $\mathrm{E}_{2}$ or DHT in HeLa cells, irrespective of whether they were transfected with the ER $\alpha$ or the AR (data not shown). These data strongly suggest that ER- or AR-dependent SRE and AP-1 regulation results from an interchangeable sex steroid-receptor interaction. In other words, ER or AR can transmit the signals for SRE and AP-1 regulation with similar efficiency irrespective of whether the ligand is an estrogen or an androgen.

Next, we sought to identify the kinases responsible for the modulation of SRE or AP-1 activities using a series of different dn mutants (Figure 2). As shown previously for the antiapoptotic effect of $\mathrm{E}_{2}$ on osteoblasts and osteocytes, $\mathrm{E}_{2}$-induced SRE activation in ER $\alpha$ transiently transfected HeLa cells was blocked by cotransfection of a dn MEK, the kinase responsible for ERK phosphorylation (Figure 2a). Similarly, the stimulatory effect of $\mathrm{E}_{2}$ was abrogated in HeLa cells transfected with the ER $\alpha$ and cotransfected with Src $\mathrm{K}^{-}$. The SRE transactivation by $\mathrm{E}_{2}$ was also abrogated by dn She mutants in which all three (FFF), or only the third (YYF) of the three tyrosines Y239, Y240, and Y317 (the primary site of Shc phosphorylation by Src), were substituted by phenylalanine. When tyrosines 239 and 240, but not 317, were mutated, however, the SRE transactivation by $E_{2}$ was unaffected. WT MEK, Src, or Shc, used as negative controls in this experiment, had no effect. We next examined the involvement of JNK or ERKs in $\mathrm{E}_{2}$-induced downregulation of AP-1 activity. Transfection of a dn JNK1 mutant into ER $\alpha$-containing cells abolished the $\mathrm{E}_{2}$-induced downregulation of AP-1-SEAP activity, without affecting basal AP-1 activity (Figure 2b). On the other hand, dn MEK did not abolish $\mathrm{E}_{2}$-induced downregulation of AP-1 activity, but it significantly decreased basal AP-1 activity, indicating that consistent with previous reports $(33,34)$, ERKs were responsible for the basal AP-1 activity. In the presence of $\mathrm{E}_{2}$, however, JNK signaling was suppressed, and this effect overrode the stimulatory effect of ERKs on AP-1. As expected, a dn AP-1 had an effect similar to the dn MEK on both basal and $\mathrm{E}_{2}$-modulated AP-1SEAP. These results establish that the regulation of

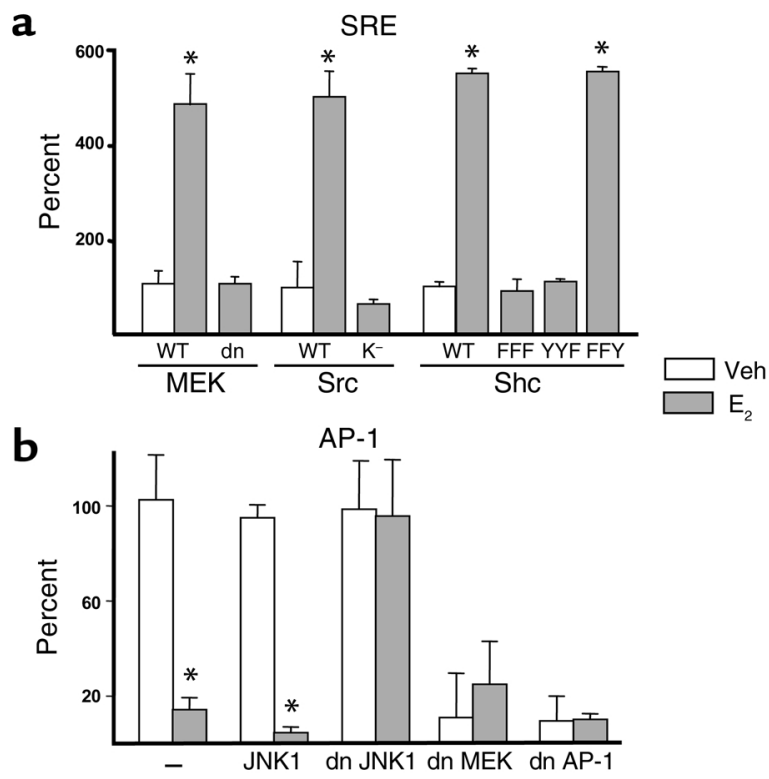

\section{Figure 2}

The transcriptional regulation of SRE and AP- 1 by estrogens requires the $\mathrm{Src} / \mathrm{Shc} / \mathrm{ERK}$ and JNK signaling pathways, respectively. HeLa cells were transfected with the SRE (a) or the AP-1 (b) reporter constructs used in Figure 1, together with the full-length ER $\alpha$. Aliquots of these cells were then also transfected with either WT or dn mutants of MEK, Src, or Shc (a). Src K- indicates a mutant lacking the kinase activity of Src; in dn Shc mutants the primary sites of phosphorylation have been substituted by phenylalanine: Y239F/Y240F/Y317F (Shc FFF), Y317F (Shc YYF), or Y239F/Y240F (Shc FFY). (b) HeLa cells were transfected with the AP-1 reporter, ER $\alpha$, and WT JNK1, dn JNK1, dn MEK, or dn AP-1. One hundred percent indicates the activity in vehicle-treated cells. Bars indicate means \pm SD of triplicate determinations; ${ }^{*} P<0.05$ versus vehicle by ANOVA. 

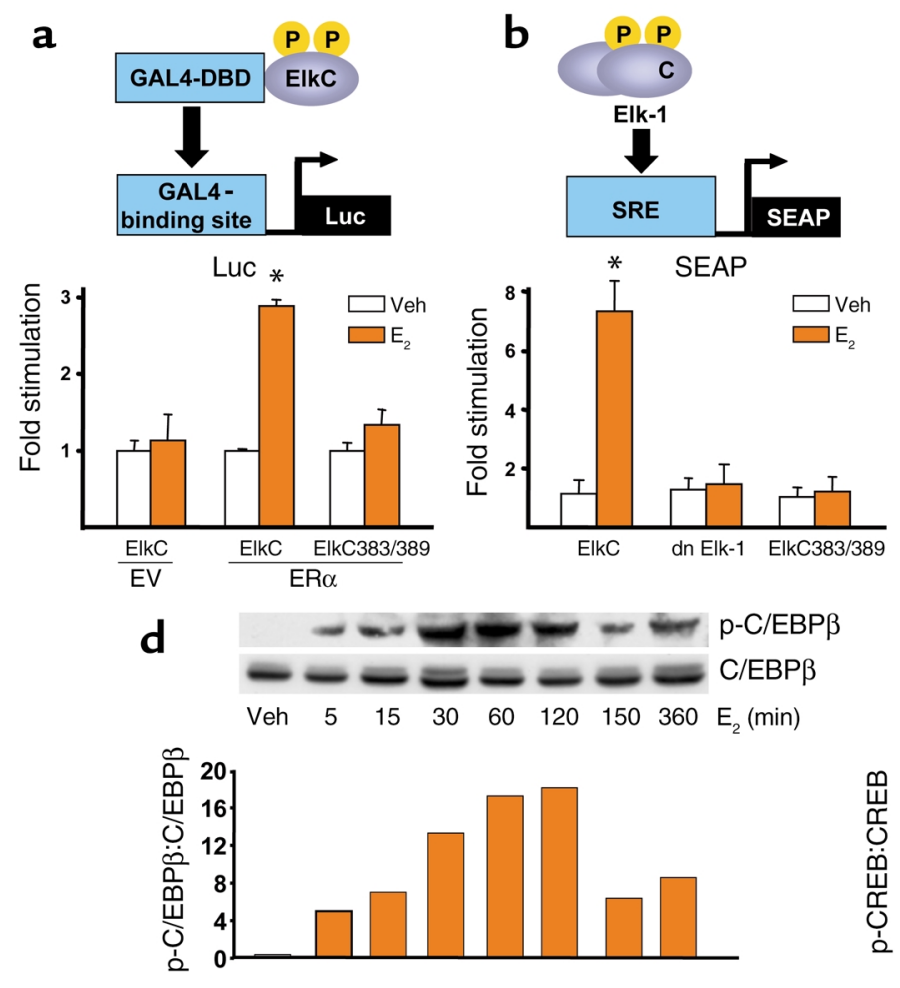
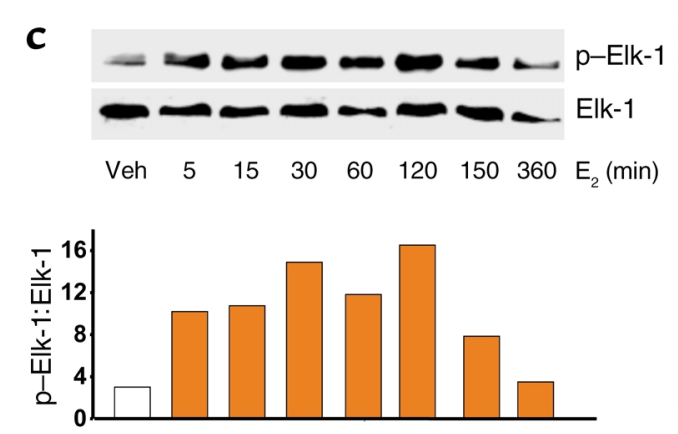

\section{Figure 3}

Estrogens induce activation of ERK-regulated transcription factors in vitro. GAL4-DBD depicts the DNA binding domain of the galactosidase gene 4, ElkC depicts the carboxy terminus of the Elk-1 molecule, P and p indicate phosphorylation. HeLa cells were cotransfected with empty vector (EV) or ER $\alpha$ and either WT GAL4-DBD-ElkC (ElkC) or the mutant GAL-ElkC383/389 (ElkC383/389) constructs. ElkC activity was measured by cotransfection of a reporter plasmid in which luciferase (luc) transcription is under the control of the GAL4-binding site (GAL4-binding site-luc) (a). HeLa cells were transfected with ER $\alpha$ and the SRE-SEAP, together with ElkC, dn Elk-1, or ElkC383/389 constructs (b). OB-6 murine osteoblastic cells were treated with $E_{2}$ for the indicated periods of time, and the phosphorylation of Elk-1, C/EBP 3 , and CREB was determined with Western blot analysis ( $\mathbf{c}$ and $\mathbf{d}$ ). In $\mathbf{c}$ and $\mathbf{d}$, numbers on the $y$ axis indicate ratios.

SRE activity results from activation of the Src/ Shc/ERK signaling cascade. Furthermore, they suggest that $\mathrm{E}_{2}$ downregulates AP-1 activity via a JNKK1/ MEKK1/JNK1 pathway, originally described to be activated by cytokines or cellular stress (35).

Requirement of Elk-1, C/EBP $\beta$ (NF-IL6), CREB, and AP-1 for the antiapoptotic effect of sex steroids. Elk-1, C/EBP $\beta$, and CREB are transcription factors that can be activated by ERKs (36-38). We therefore proceeded to examine whether transcription in general and these factors in particular were involved in the activation of SRE and the antiapoptotic effects of estrogens. First, we examined whether $E_{2}$ induces Elk-1 phosphorylation and thereby activation by cotransfecting HeLa cells with empty vector or ER $\alpha$ and either WT or dn mutants of Elk-1. Specifically, for WT control we used the C-terminal domain of Elk-1 (amino acids 307-428), which is the part of the protein that is phosphorylated by MAPK at multiple sites (39). When this domain is fused to the DNA-binding domain of GAL4 (GAL-ElkC), it can function as a transactivation domain, the activity of which can be measured on a GAL4-dependent promoter construct. As dn Elk-1 mutant we used a GALElkC383/389 construct in which serines 138 and 139, the targets of phosphorylation by ERKs, are substitut- ed for phenylalanines (19). The results depicted in Figure 3 a demonstrate that $\mathrm{E}_{2}$ induced reporter gene activity in HeLa cells cotransfected with ER $\alpha$ and the GALElkC and GAL4-luciferase constructs. This response required the presence of $E R \alpha$, since HeLa cells transfected only with the GAL-ElkC, and GAL4-luciferase constructs did not exhibit reporter activity. On the other hand, when the phosphorylation-inactive GALElkC383/389 mutant was used instead of the WT GALElkC constructs, the ability of $E_{2}$ to induce GAL4luciferase expression was completely lost. Similar results were obtained in two additional experiments, indicating that $E_{2}$ activates Elk-1 by a ER $\alpha$-mediated mechanism that requires ERK signaling.

The possibility that activation of Elk-1 mediates the $\mathrm{E}_{2}$-induced SRE activity was examined in HeLa cells cotransfected with the ER $\alpha$, the SRE-SEAP reporter plasmid, and either the GAL-ElkC, the GALElkC383/389 mutant, or Elk-1 missing its DNA-binding domain (dn Elk-1; see ref. 19) (Figure 3b). In cells containing the WT control GAL-ElkC, $\mathrm{E}_{2}$ induced activation of SRE. This effect was completely blocked in cells expressing dn Elk-1 or the phosphorylation-inactive GAL-ElkC383/389 mutant. Phosphorylation of Elk-1 in response to $\mathrm{E}_{2}$-treatment was demonstrated in 
the OB-6 murine osteoblastic cell line by Western blot analysis. $\mathrm{E}_{2}$ rapidly and transiently increased the phosphorylation of Elk-1, with a maximal effect seen at 5 minutes to 2 hours after treatment and a return to baseline by 6 hours (Figure 3c). These findings tightly link the nongenotropic, ER-induced activation of the $\mathrm{Src} / \mathrm{Sh} /$ ERK signaling cascade to the genotropic effects of Elk-1 activation and SRE-dependent gene transcription. Similar to Elk-1, $\mathrm{E}_{2}$ induced transient activation of $\mathrm{C} / \mathrm{EBP} \beta$ with a maximal effect observed at 30 minutes to 2 hours after treatment and a return to base line by 6 hours (Figure 3d). CREB was also phosphorylated by $E_{2}$, but this effect occurred at 60 minutes and was still present after 6 hours. Qualitatively similar results to those shown in Figure 3, c and d, have been reproduced in two more experiments. In full agreement with these data,
ERK-mediated stimulation of SRE activity by $E_{2}$ has been demonstrated in other cell types $(19,40,41)$, establishing that some nongenotropic actions do lead to changes in gene transcription.

The RNA synthesis inhibitor actinomycin D or the protein synthesis inhibitor cyclohexamide, at doses that inhibited ${ }^{3} \mathrm{H}$-uridine or ${ }^{3} \mathrm{H}$-leucine incorporation, respectively (Figure 4a), without affecting cell viability, abrogated the protective effect of $\mathrm{E}_{2}$ on etoposideinduced apoptosis of murine calvaria-derived osteoblasts (Figure $4 \mathrm{~b}$ ), indicating that transcription is required for antiapoptosis. Overexpression of a dn Elk-1 or a MAPK-transactivation inactive Elk-1 mutant, but not the WT control, abrogated the antiapoptotic effect of $E_{2}$ (Figure $4 c$ ). The protective effect of $E_{2}$ on apoptosis was also abrogated by dn mutants of C/EBP $\beta$ or
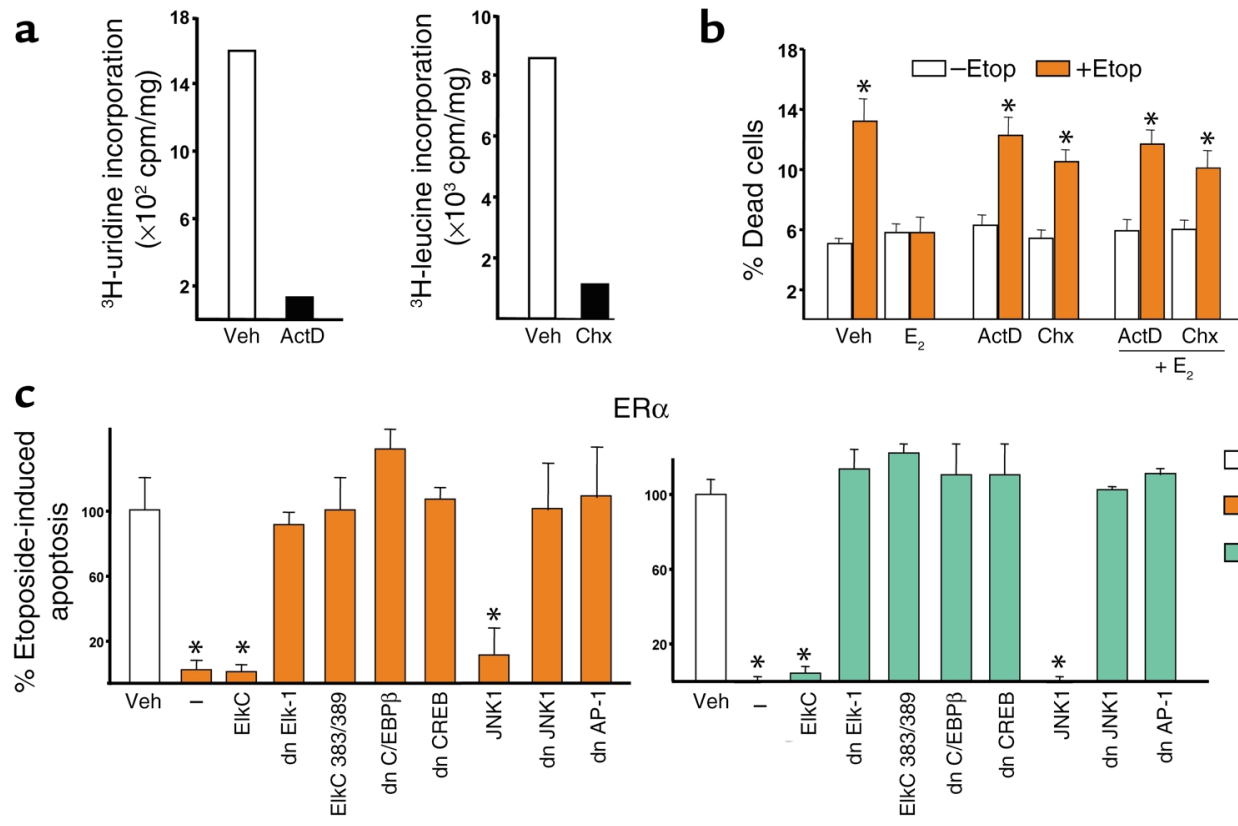

$\mathrm{ER} \alpha$
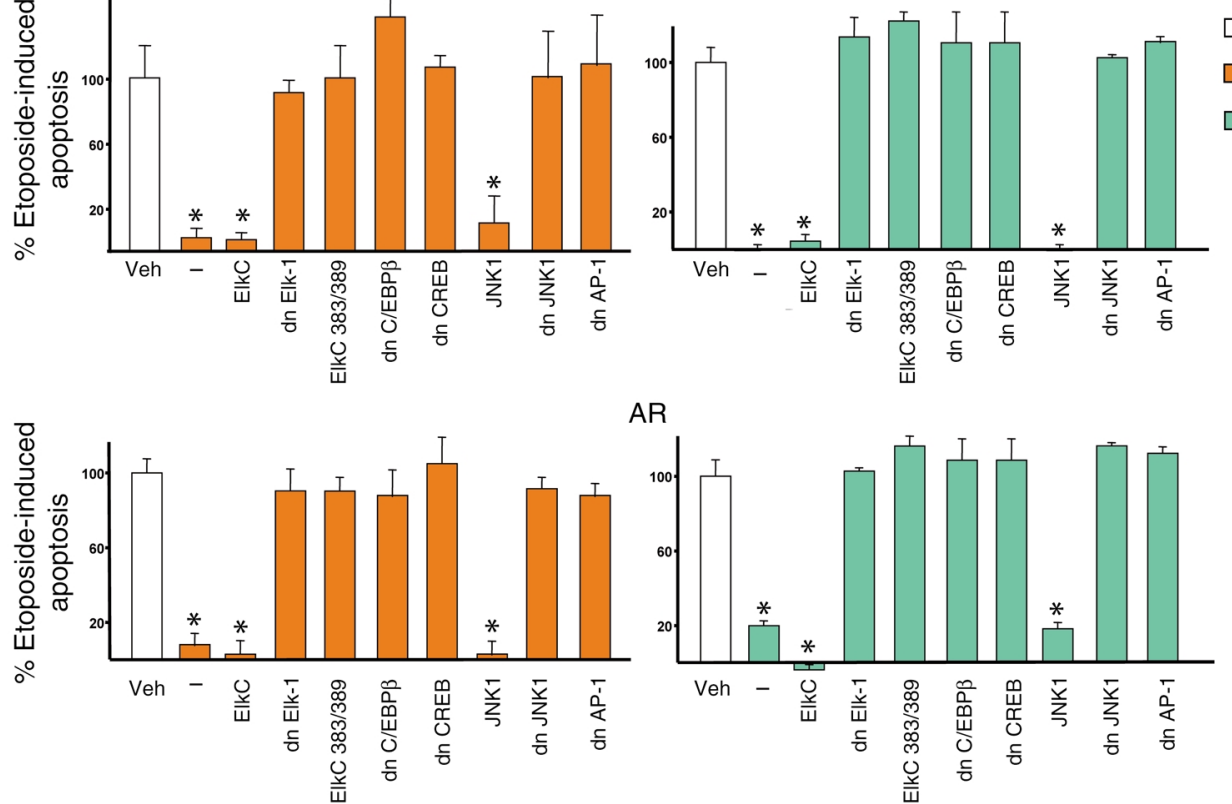

AR
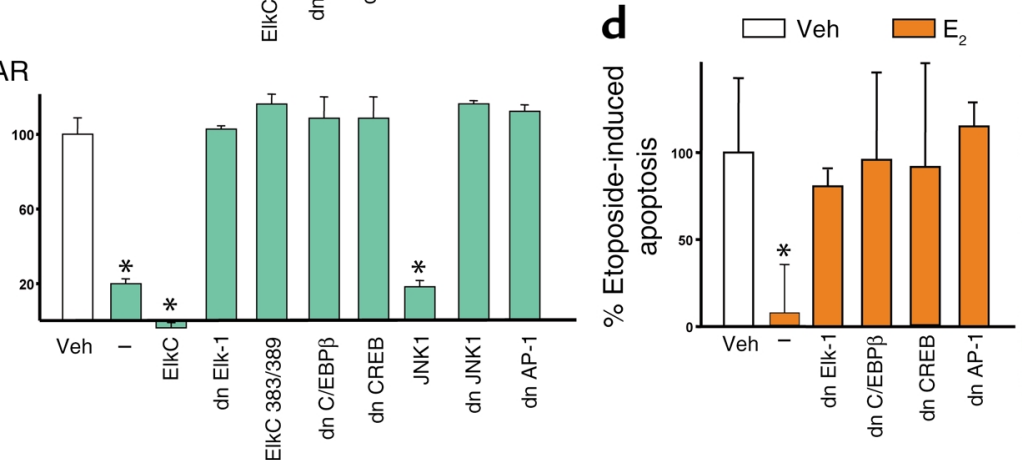

\footnotetext{
Transcrip
} or Chx for 1 hour, followed by 1 hour tre sis was then assayed by trypan blue uptake. HeLa cells were transfected with a GFP targeted to the nucleus and cotransfected with the ER $\alpha$ or the AR and the WT or dn mutants of the indicated transcription factors (c). After a 24-hour period, cells were treated for 1 hour with $10^{-8} \mathrm{M} \mathrm{E}_{2}$ or DHT followed by 6 -hour treatment with etoposide $(100 \mu \mathrm{M})$. Apoptosis was assayed by direct visualization of changes in nuclear morphology. MLO-Y4 osteocytic cells were transfected with nuclear-targeted GFP and cotransfected with the ER $\alpha$ or the AR and the WT or dn mutants of the indicated transcription factors (d). After a 24-hour period, cells were treated for 1 hour with $10^{-8} \mathrm{M} \mathrm{E} \mathrm{E}_{2}$ followed by a 6 -hour treatment with etoposide $(100 \mu \mathrm{M})$. Apoptosis was assayed as in $(\mathbf{b})$. Bars indicate means \pm SD of triplicate determinations; ${ }^{*} P<0.05$ versus vehicle by ANOVA. 
a
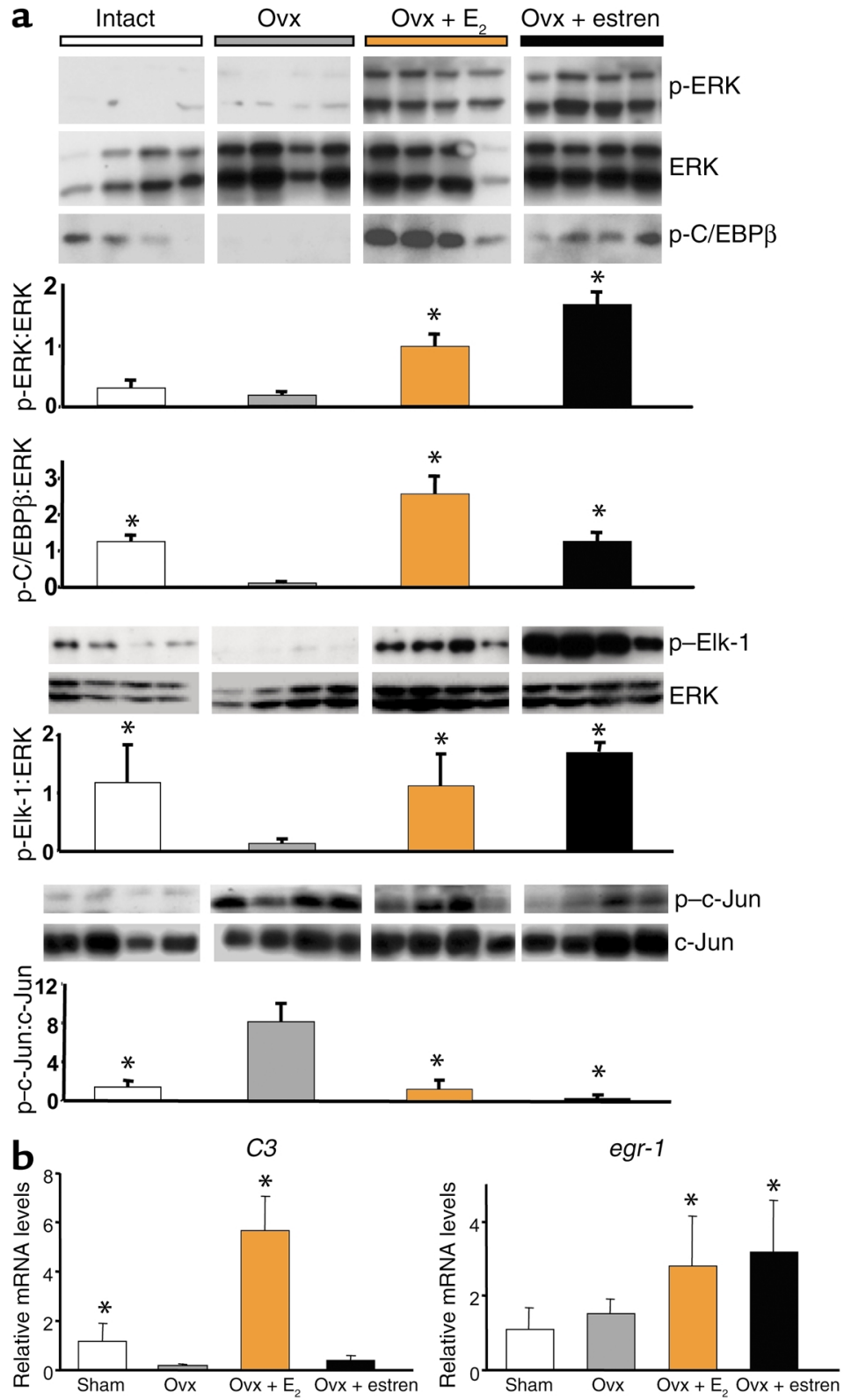

\section{Figure 5}

$E_{2}$ and estren induce phosphorylation of ERKs and their downstream targets, $C / E B P \beta$ and Elk-1, and suppress c-Jun activity in vivo. Ten-week-old Swiss Webster mice were ovx, left untreated for 5 days, and then implanted with 21-day slow-release pellets containing $E_{2}(0.01 \mathrm{mg})$ or estren $(2.6 \mathrm{mg})(\mathbf{a})$. Forty-eight hours later, ERK, $\mathrm{C} / \mathrm{EBP} \beta$, Elk-1, and c-Jun phosphorylation was determined in L5 vertebrae; each lane represents one mouse. In a separate experiment, 6-month-old Swiss Webster mice were sham-operated or ovx. The ovx animals were then left untreated or implanted immediately with 60-day slow-release pellets containing $\mathrm{E}_{2}(0.025 \mathrm{mg})$ or estren $(7.6 \mathrm{mg})(\mathbf{b})$. Six weeks later, total RNA from uteri $(n=4)$ was isolated. C3 and egr-1 expression was quantified by real-time PCR. Bars indicate means \pm SD of triplicate determinations. ${ }^{*} P<0.05$ versus ovx by ANOVA.

C/EBP $\beta$ and Elk- 1 in vivo was demonstrated by Western blot analysis using the L5 vertebrae of intact or ovariectomized (ovx) mice receiving either ligand (Figure 5a). Due to the rapid and transient nature of ERK and $\mathrm{C} / \mathrm{EBP} \beta$ activation in vitro and the fact that compounds administered as pellets reach steady-state level in the blood between 24 and 48 hours, treatments were applied for the short period of 48 hours. Administration of $E_{2}$ or estren increased ERK phosphorylation over the ovx controls. Moreover, phosphorylated CEBP $\beta$ and Elk-1 were decreased in ovx mice, and $E_{2}$ or estren reversed these changes. Furthermore, in agreement with our in vitro observations that $\mathrm{E}_{2}$ or estren suppresses AP-1-SEAP activity, either compound decreased c-Jun phosphorylation. Estren was seemingly more potent than $\mathrm{E}_{2}$ in suppressing c-Jun activity, however. We have shown previously that estren, unlike $E_{2}$, is ineffective in upregulating the ERE-mediated expression of the complement 3 (C3) gene in

CREB. Lastly, the antiapoptotic effect of $\mathrm{E}_{2}$ was abolished by dn constructs for JNK1 or AP-1, but not a WT JNK1, in line with the finding that $\mathrm{E}_{2}$ downregulates AP-1-SEAP activity. The dn Elk-1, C/EBP $\beta$, CREB, JNK1, and AP-1 also abrogated the protective effect of DHT in ER $\alpha$-transfected cells. Moreover, in keeping with the interchangeable ligand-receptor interaction, the effects of DHT or $\mathrm{E}_{2}$ were abrogated in HeLa cells transfected with the AR and each of the dn mutants. The effects of dn Elk-1, C/EBP $\beta$, CREB, and AP-1 were confirmed using the osteocytic MLO-Y4 cells that express endogenously ER $\alpha$ and ER $\beta$, but not AR (Figure 4d). These findings indicate that modulation of transcription factor activity by sex steroids is required for antiapoptosis.

Kinase-mediated activation of transcription factors by $E_{2}$ and estren in vivo. The ability of $\mathrm{E}_{2}$ or estren to phosphorylate ERKs and the ERK-activated transcription factors the uterus under conditions in which it increases bone mass in ovx female mice without affecting the weight of the uterus (11). Consistent with this finding, $\mathrm{E}_{2}$ but not estren increased the expression of $\mathrm{C} 3$ in the uterus, whereas both compounds induced the expression of egr -1 , a gene that is activated by $\mathrm{E}_{2}$ via the ERK/SRE pathway (40) (Figure 5b).

Transcription-independent events downstream of kinases are also required for the antiapoptotic effects of sex steroids. Kinases modulate cell survival not only through changes in gene transcription, but also through modification of the functional activity of proteins, independent of any transcriptional changes $(37,42)$. Furthermore, there is evidence that both ERKs and PI3K induce phosphorylation, and thereby inactivation, of the proapoptotic protein Bad (43-46). We therefore investigated whether the antiapoptotic effect of estrogens, or estren, requires 
convergence of these two signaling cascades on Bad. Wortmannin, a PI3K inhibitor, attenuated the antiapoptotic effect of $\mathrm{E}_{2}$ and estren in calvaria cells (Figure 6a). PI3K can inactivate Bad by activation of either Rsk2 (37) or the Akt serine-threonine kinase (47). A dn Rsk2 but not a dn AKT or the WT forms of these kinases abolished these actions in HeLa cells (Figure 6b), demonstrating that Rsk2, but not Akt, is required for the antiapoptotic actions of $E_{2}$. Furthermore, ER $\alpha$ transfected HeLa cells expressing a dn Bad mutant (dn Bad AAA), which cannot be phosphorylated, failed to respond to either ligand, indicating that phosphorylation and inactivation of $\mathrm{Bad}$ was indispensable for the antiapoptotic actions of $E_{2}$ or estren (Figure $6 c$ ). In studies not shown here, wortmannin, as well as the inhibitor of ERK activation, PD98059, abolished $\mathrm{E}_{2}$ induced phosphorylation of Bad.

Raloxifene does not share the nongenotropic effects of estren. Raloxifene, a synthetic selective estrogen receptor modulator (SERM) has dissociated actions on bone versus the uterus, being an agonist in the former and a pure antagonist in the latter. We therefore examined whether raloxifene has similar or different effects compared with those of estren on apoptosis and the signaling pathways activated by the estren. Sharply different from estren, raloxifene had a minimal effect (four orders of magnitude less potent than estren) on the prevention of etoposide-induced apoptosis in murine osteoblastic calvaria cells (Figure 7a) and no effect on etoposideinduced apoptosis of osteocytic MLO-Y4 cells (data not shown) or HeLa cells transfected with the ER $\alpha$ or the AR (Figure 7b). Likewise, unlike estren, raloxifene at concentrations as high as $10^{-7} \mathrm{M}$ had no effect on the induction of apoptosis in murine osteoclasts (Figure $7 \mathrm{c}$ ). Consistent with its inability to prevent apoptosis, raloxifene was unable to activate SRE in ER $\alpha$-transfected HeLa cells (Figure 7d). Raloxifene, but not estren, suppressed PMA-induced IL-6 transcription, however, confirming the well-appreciated estrogen-like efficacy of the former compound on classical transcription (Figure 7e). Furthermore, in contrast to estren, raloxifene failed to induce rapid phosphorylation of ERK-1 and -2 (Figure 7f) or to promote accumulation of ERK-2 in the nucleus (Figure 7g) in MLO-Y4 cells. Finally, we examined whether raloxifene was capable of phosphorylating ERKs in vivo by performing Western blot analysis of protein extracts from the L 5 vertebrae of ovx mice receiving two different doses of estren or raloxifene, using an experimental protocol identical to that described in Figure 5. In this experiment estren was administered to mice at a dose identical to that used in the experiments described in Figure 5 and also a dose ten times higher, corresponding to one and ten times the $K_{\mathrm{d}}$ of estren for the ER $\alpha$. By analogy, the two doses of raloxifene corresponded to three times and 30 times the $K_{\mathrm{d}}$ of raloxifene for the $\mathrm{ER} \alpha(48)$. These doses have been shown previously to be effective on the bone of mice and rats (49-53) and represent a threefold or 30fold excess of the replacement dose of $\mathrm{E}_{2}$. Confirming the results of the experiment of Figure 5, administration of estren in this experiment increased ERK phosphorylation over the ovx controls. At either one of the concentrations used, however, raloxifene administration had no effect on ERK phosphorylation.

\section{Discussion}

The results presented in this paper demonstrate several paradigms of ER- or AR-mediated effects on gene transcription that originate outside the nucleus. In all cases the effect can be elicited using only the ligandbinding domain of the classical ER and comprises a three-stage cascade of events: (a) modulation of cytosolic kinases (ERKs or JNK), (b) kinase-mediated alteration of the activity of transcription factors, and (c) transcription factor-dependent upregulation or downregulation of gene expression. Each one of several tran-
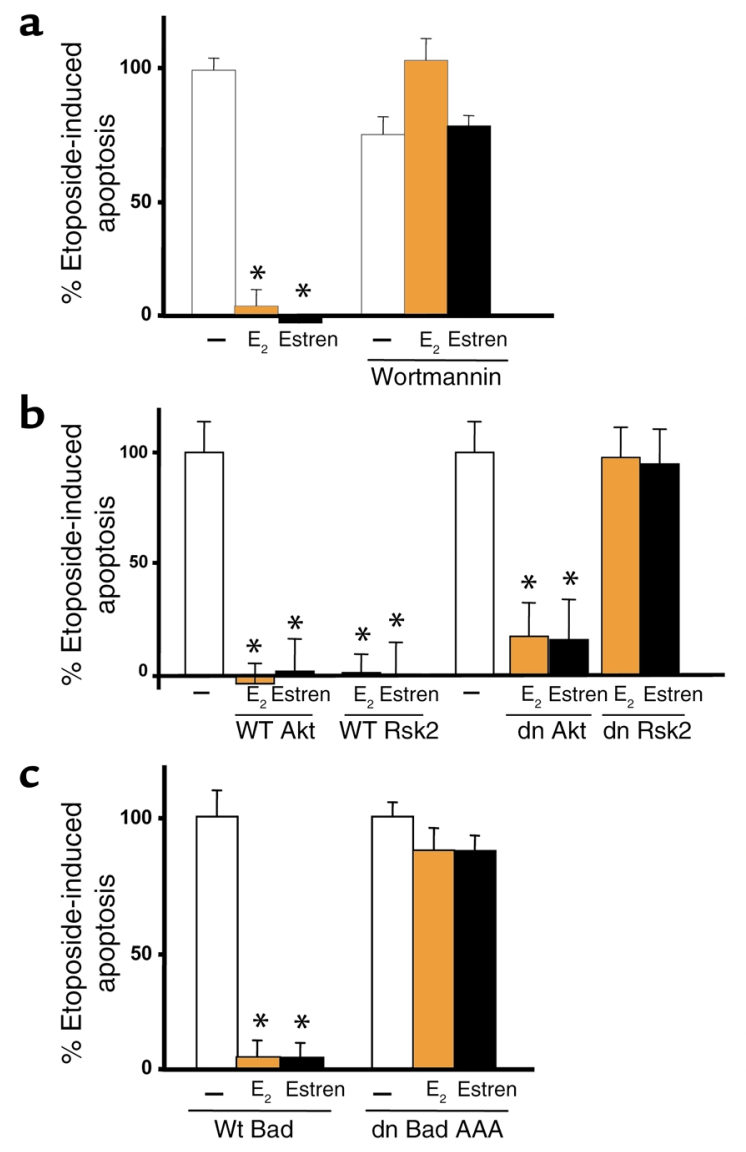

\section{Figure 6}

Transcription-independent events downstream of kinases are also required for the antiapoptotic effects of sex steroids. Calvariaderived murine osteoblastic cells were pretreated with the $\mathrm{PI} 3 \mathrm{~K}$ inhibitor wortmannin $(30 \mathrm{nM})$ for 1 hour, at which point $E_{2}$ was added to the culture. One hour later, etoposide was added, and the cultures were continued for an additional 6 hours (a). (b and $\mathbf{c}$ ) HeLa cells were transiently transfected with the ER $\alpha$ and nuclear GFP. The cells were also cotransfected with WT or dn mutants of Rsk2 or AKT (b) or a nonphosphorylatable dn mutant of Bad (c). Cells were then treated as in a (c). Bars indicate means \pm SD of triplicate determinations; ${ }^{*} P<0.05$ versus vehicle by ANOVA. 

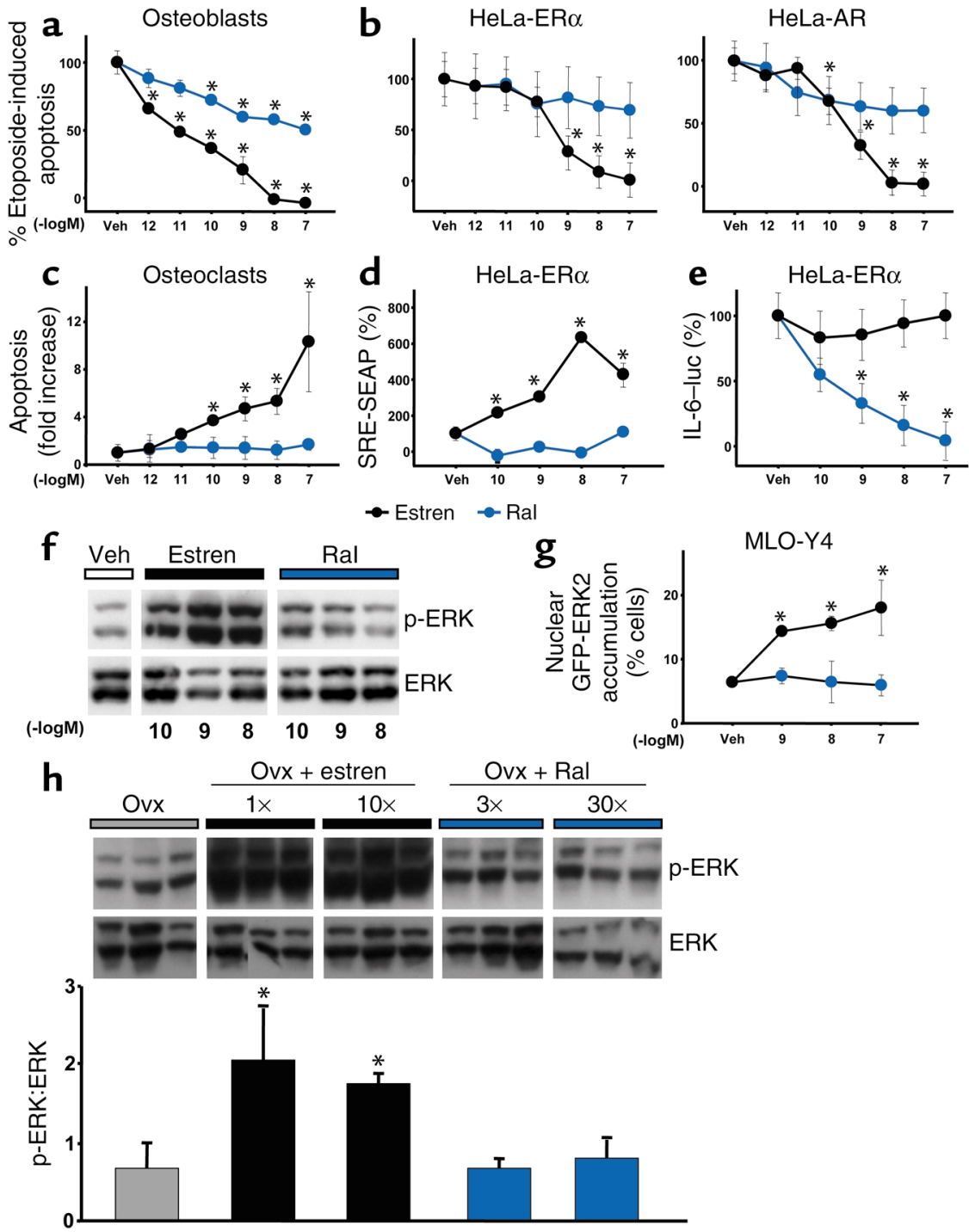

\section{Figure 7}

Raloxifene does not mimic the nongenotropic effects of estren. Calvaria cells were pretreated with estren or raloxifene (Ral) and then exposed to etoposide as described in Figure 4b. Apoptosis was assayed by measuring caspase- 3 activity in cell lysates (a). HeLa cells were transiently transfected with ER $\alpha$ or AR and the pCaspase3-Sensor vector $(\mathbf{b})$. Osteoclasts were treated with the indicated concentrations of the two compounds for 24 hours, and apoptosis was assayed as described in a (c). HeLa cells were cotransfected with $E R \alpha$ and either SRE-SEAP (d) or IL-6-luciferase (IL-6-luc) (e) reporters, and SRE-SEAP activity was assessed as in Figure 1. PMAinduced IL- 6 activity was determined as described in Methods. SRE-SEAP or IL-6luciferase activity in the presence of vehicle is designated as $100 \%$. MLO-Y4 cells were incubated for 5 minutes with estren or Ral, and ERK phosphorylation was assayed by Western blot analysis (f). GFP-ERK2 nuclear accumulation was assessed as in Figure $1 \mathrm{~b}(\mathbf{g})$. Ten-week-old Swiss Webster mice were ovx, left untreated for 5 days, and then implanted with 21-day slowrelease pellets containing estren $(2.6 \mathrm{mg}$ or $26 \mathrm{mg}$ ) or Ral ( $0.027 \mathrm{mg}$ or $0.27 \mathrm{mg}) ; 1 \times$, $10 \times, 3 \times$, or $30 \times$ refers to the correspondence of the given dose to the $K_{\mathrm{d}}$ of the respective compound for ER $\alpha$. Forty-eight hours after pellet implantation, the animals were sacrificed and ERK phosphorylation was determined in protein extracts from L5 vertebrae; each lane represents one mouse $(\mathbf{h})$. Bars indicate means $\pm S D$ of triplicate determinations; ${ }^{*} P<0.05$ versus vehicle or ovx by ANOVA. scription factors is required for the antiapoptotic effect of estrogens or androgens in bone and other cell types in vitro. Furthermore, all these effects can be demonstrated in bone following administration of estren or $\mathrm{E}_{2}$ to ovx mice. These observations clearly establish that the distinction between nongenotropic actions of sex steroids (on kinases) and genotropic actions is more apparent than real in the sense that, at least in some instances, the former lead to the latter. For the lack of a better term, we suggest that the choice of the word "nongenotropic" over the most commonly used "nongenomic" is an appropriate one to describe kinaseinitiated effects of sex steroids, based on several of the meanings of the Greek suffix (tropic): "turn toward", "having an affinity for", or "affecting the activity of" (e.g., gonadotropic) (54).

In addition to the evidence that the antiapoptotic effect of estrogens or androgens involve the modulation of transcription factors downstream of at least two kinase-initiated signaling transduction cascades (ERKs and JNK), we have demonstrated here that the anti- apoptotic effects of sex steroids require kinase-mediated modification of the functional activity of proteins, independent of any transcriptional changes. Specifically, we show that activation of PI3K and ERK signaling by sex steroids leads to the phosphorylation and inactivation of the proapoptotic protein Bad, most likely through an effect of Rsk2. This line of evidence is in full agreement with the results of studies in neuronal and hematopoietic cells, highlighting the requirement of both transcription-dependent and -independent mechanisms in the survival signals transduced by ERKs $(37,42)$. A diagrammatic representation of the kinaseinitiated signaling pathways and their downstream effectors required for the antiapoptotic effects of sex steroids is depicted in Figure 8.

Integration of sex steroid signals with local growth factors and physicomechanical environmental cues. The elucidation of kinase-initiated routes by which sex steroids can exert transcriptional control reveals previously unappreciated means by which these hormones regulate a range of genes much wider than that which can be regulated by 
classical transcriptional mechanisms alone, i.e., through ERE or protein-protein interaction of their receptors. Elk-1, C/EBP $\beta$, CREB, c-Jun/c-Fos are ubiquitous factors used by a plethora of local and systemic growth factors as well as multiple physicochemical and mechanical stimuli. Consequently, modulation of the activity of the transcription factors by sex steroids through modulation of the activity of cytoplasmic kinases provides an appealing combinatorial cell response mechanism integrating cues arriving from afar, i.e., the change in the production of sex steroids, to more proximal environmental cues such as changes in the concentration of locally produced growth factors or mechanical and physical strains. In such a way, a target cell at a particular site may rapidly adapt its response to the sex steroid signal arising from afar to unique microenvironmental circumstances. For example, in the context of antiapoptotic effects of estrogens and androgens on osteoblasts or their proapoptotic effects on osteoclasts (also mediated via nongenotropic activation of kinases; see refs. 11,55), such effects may not involve universally every osteoblast or osteoclast in the skeleton. Instead, they may involve only osteoblasts and osteoclasts restricted within discrete microanatomical environs defined, for example, by a particular biochemical milieu, or the adhesion molecules controlling the avidity of the cells' attachment to their matrix, or the magnitude of mechanical strains exerted upon them.

Whereas sex steroids preserve bone mass, estren, which, as shown here, faithfully reproduces the nongenotropic effects of sex steroids without affecting classical transcription, increases bone mass in ovx females above the level of the estrogen-replete mice without affecting ERE-mediated transcription (11). How could elimination of the genotropic effects of sex steroids, as occurs with estren, lead to a superior effect on bone? We conjecture that the superior effect of estren results not only from its favorable effects on bone cell apoptosis, but also additional mechanisms such as an upregulation of osteoblastogenesis or promotion of progenitors toward mature osteoblasts at specific sites (e.g., the cortices of long bones). This hypothesis is consistent with the breadth of the effects of estren on the activation of several ubiquitous transcription factors described here, which have been widely implicated in the pathways that promote bone growth. In contrast to our finding that activation of MAP kinases by an extranuclear function of the ER $\alpha$ suppresses AP-1 activity, Kushner and coworkers have shown that $\mathrm{E}_{2}$-activated $\mathrm{ER} \alpha$ stimulates $\mathrm{AP}-1$ activity by a genotropic mechanism (56). It is therefore likely that the response of a target cell to sex steroids may be determined by the balance between nongenotropic and genotropic actions. Hence, the superior effects of estren on bone could very well result from the removal of a counterregulatory effect on AP-1. We have hypothesized before (11) that a greater suppression of c-Jun could lead to decreased transcription of the Wnt antagonist, Dickkopf, thereby unleashing Wnt signaling - a potent bone anabolic stimulus $(57,58)$. Demonstration of downregulation of c-Jun in the vertebrae of ovx mice treated with $\mathrm{E}_{2}$ or estren in this study adds strong support to this hypothesis.

Relaxed specificity of the effects of sex steroids on nonreproductive tissues. The development, growth, maintenance, and function of reproductive tissues depend, by and large, on estrogens in females and androgens in males. A rapidly growing body of recent clinical observations and experimental results, however, strongly suggests that the sex specificity of the effects of sex steroids on nonreproductive tissues is greatly relaxed. For example, estrogens are as effective in males as they are in females at protecting against bone loss, lowering cholesterol, or slowing atherosclerosis (59-67). Conversely, nonaromatizable androgens promote relaxation of the thoracic aorta (68) and, as determined by us in unpublished studies, prevent bone loss in ovx adult females. The studies reported here offer mechanistic explanations for these observations. Specifically, they demonstrate an interchangeable profile of ligand-receptor specificity in the regulation of the activity of ubiquitous transcription factors such as Elk-1, C/EBP $\beta$, CREB, and c-Jun/c-Fos.

In full agreement with these findings, we have demonstrated that the effects of estrogens and androgens on the survival of osteoblasts and osteoclasts in vitro and of osteoblasts in vivo (11) are equivalent. In unpublished studies we have also determined equivalence of the effects of estrogens and androgens in the protection against loss of bone mineral density (BMD) in both males and females. Furthermore, we have determined that $E_{2}$ stimulates ERK phosphorylation (55), prevents osteoblast apoptosis, and stimulates osteoclast apoptosis in cells from double estrogen receptor knockout (DERKO) mice lacking both ER $\alpha$ and $\mathrm{ER} \beta$ or any variant of these proteins (69) and that this effect can be abrogated by silencing the AR. Consistent with an ARmediated effect of estrogens, and vice versa, mature

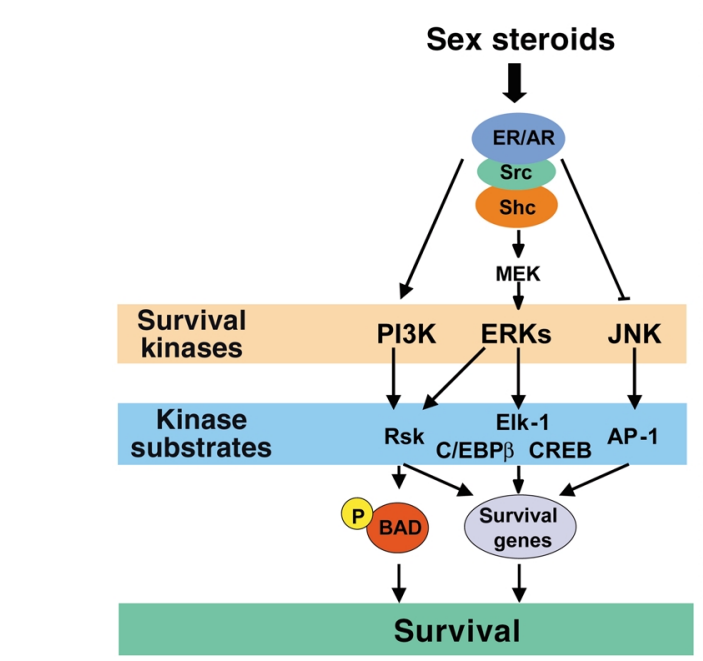

Figure 8

Outline of kinase-initiated signaling pathways and downstream effectors required for the antiapoptotic effects of sex steroids. 
7-month-old DERKO mice lose bone following ovx; this can be prevented by administration of $\mathrm{E}_{2}(70,71)$. Nonetheless, based on results from the study of an $\mathrm{ER} \alpha^{-/-}$mouse (not an $\mathrm{ER} \alpha \beta^{-/-}$mouse as mistakenly claimed in the abstract), Sims et al. have suggested that the $\mathrm{AR}$ cannot substitute for $\mathrm{ER} \alpha$ to mediate $\mathrm{E}_{2}$ protection against gonadecomy-induced bone loss in male or female mice (72). Unfortunately, the use of tibial metaphyses from growing mice (12 weeks old) to examine the effects of sex steroid deficiency in that paper precludes any conclusions about bone loss. All the metaphyseal cancellous bone present at 12 weeks would have been resorbed with or without gonadectomy. All of the bone illustrated 4 or 8 weeks later was made during the experiment, and its amount could be reduced not only because too much was resorbed, but also because too little was formed at the growth plate, for which there are many possible reasons (67). Furthermore, the conclusion that estrogens cannot act through the ER was based on the paradox that ER $\beta$ was able to mediate bone effects of $E_{2}$ in females but not in males. In sharp contrast to the findings of Sims et al., mature 6-monthold orchidectomized $\mathrm{ER}^{-/-}$mice do respond to $\mathrm{E}_{2}$ with increased cortical thickness, high serum alkaline phosphatase, and increased bone formation at the endocotical surface (73). These inconsistencies notwithstanding, the purported effects of testosterone through the AR in the ER $\alpha^{-/-}$male mice of the Sims report are exactly the opposite of the effects of androgen on a human male with an inactivating mutation of ER $\alpha$ (74), even though both mice and humans exhibit high testosterone levels and normal AR function: low, as opposed to high, bone turnover and increased, as opposed to decreased, bone density. Studies with animals in which both ERs as well as the AR are deleted subsequent to reaching skeletal maturity ultimately will be required to directly test the notion that interchangeable ligand receptor interaction is the most likely mechanistic explanation for the relaxed sex specificity of the actions of estrogens and androgens on bone.

Activators of nongenotropic estrogen-like signaling are not SERMs. Based on the evolution of our understanding of the mechanism of action of estren and its unique biological profile in vivo $(10,11)$ further delineated here, as well as the semantic distinction between the terms genotropic and genomic that we discussed above, we now use the term "activators of nongenotropic estrogen-like signaling (ANGELS)" to define small (nonphenolic) molecules that mimic the nongenotropic actions of estrogens (and androgens) but lack their classical genotropic effects. Do ANGELS, as defined here, represent an entirely unique and altogether novel class of compounds, as we had proposed earlier? The earlier published evidence, taken together with the data presented here, clearly support the notion that they do. Indeed, not only do the actions of estren differ mechanistically from classical estrogens or androgens (since this compound is completely devoid of classical genotropic actions), but also, as shown here, they dif- fer greatly from raloxifene, a prototypic SERM, which also dissociates estrogenic effects on bone versus reproductive organs such as the uterus. Importantly, we determined here that the lack of uterotropic effects of estren (11) cannot be due merely to complete lack of action of this compound on the uterus because clearly estren was as effective as estradiol in increasing the expression of the egr-1 gene that is activated via the ERK/SRE pathway; however, it was incapable of stimulating the expression of $\mathrm{C} 3$. On the other hand, raloxifene, an ER agonist on bone but pure ER antagonist in the uterus, did not exhibit any of the nongenotropic effects of estren, or for that matter classical estrogens, on ERK/SRE signaling and bone cell apoptosis; however, sharply distinct from estren, raloxifene was as effective as estradiol in suppressing the transcription of the IL- 6 gene. In the context of skeletal effects it is important also to note that estren administration to ovx mice increases serum osteocalcin (11), a serum marker of osteoblast number, whereas raloxifene under those circumstances decreases osteocalcin, evidently by slowing the rate of bone remodeling $(52,75)$. In studies not shown here we have found that hydroxy-tamoxifene and idoxifene, similar to estradiol and the estren, do have antiapoptotic effects on osteoblastic cells in vitro (76), indicating that lack of nongenotropic actions is not a general property of all compounds designated as SERMs.

The skeletal effects of raloxifene are weaker than those of classical estrogens in rats and mice, as well as humans. Indeed, despite the fact that raloxifene has similar affinity for the ER $\alpha$ or ER $\beta$ as classical estrogens (48), when administered to rodents at doses similar to those of estradiol, it is completely ineffective on bone, and at doses 30 -fold higher than those used for estradiol, it is still weaker on BMD and the suppression of serum osteocalcin (49-52). Furthermore, the published work of others (77), as well as unpublished work from our group (R.S. Weinstein et al., unpublished observations), shows that in humans raloxifene is only one-third as effective as classical estrogens on BMD. Whether the lack of nongenotropic actions of raloxifene or its inability to modulate the life span of osteoblasts, osteocytes, or osteoclasts (despite its estrogen-like genotropic activity) plays a role in the weaker antiosteoporotic efficacy of this compound, compared with classical hormone replacement therapy (77) or bisphosphonates (78), will require further studies.

In summary, we have delineated here signaling cascades that are triggered by the modulation of cytoplasmic kinases by sex steroids and lead to the control of gene transcription by ubiquitous transcription factors. In addition, we have demonstrated that one can effectively dissociate such kinase-mediated regulation of transcription factors from the classical genotropic actions of the sex steroid receptors with synthetic ligands. In full agreement with the portion of our in vitro data dealing with Elk-1, Duan and coworkers (19), as well as Song et al. (41), have shown recently that $\mathrm{E}_{2}$ induces the expres- 
sion of the protooncogenes $c$-fos or upregulates the activity of a reporter construct in MCF-7 human breast cancer cells via ER-mediated activation of the SRE through MAPK-dependent phosphorylation of Elk-1. Similarly, de Jager et al. have shown that estrogens, acting through the classical ERs (both $\alpha$ and $\beta$ ), induce the transcriptional activation of egr-1 from two SRE sites in primary cardiomyocytes through ERK-1 and -2 (40). Our results, taken together with these observations of others, indicate that the ability of estren to stimulate nongenotropic pathways may not be limited to an individual cell type, organ, or tissue. Based on this and evidence that the nongenotropic regulation of kinases is sufficient for the protective effects of sex steroids on nonreproductive tissues such as bone, but dispensable for their effects on reproductive tissues (11), we propose that regulation of transcription factors via kinase signaling provides the molecular underpinning of the striking and profound biologic consequences of selectively activating nongenotropic actions of sex steroids. Consequently, ANGELS and, perhaps, activators of nongenotropic signals of other nuclear receptors may represent a novel class of pharmacotherapeutics with the potential of biologic outcomes distinct from those produced by the natural ligands that activate genotropic and nongenotropic signals alike or synthetic ligands that activate only the former.

\section{Acknowledgments}

The authors wish to thank John A. Katzenellenbogen for providing the pyrazole used in these studies; S. Safe, M. Karin, W.C. Horne, K.S. Ravichandrian, N.G. Ahn, M.E. Greenberg, R.J. Davis, X.-M. Zhou, C. Vinson, T. Chambers, and R. Seger for the provision of plasmids; Scott A. Stewart for help with statistical analyses; and Michelle Douglas for the preparation of the manuscript. This research was supported with grants from the NIH (P01-AG13918 to S.C. Manolagas; KO2-AR02127 to T. Bellido), the Allied Signal Award for Research on Aging, the Department of Veterans Affairs (Veterans Affairs Merit Review and a Research Enhancement Award Program to S.C. Manolagas), and Anabonix Inc.

1. McKenna, N.J., and O'Malley, B.W. 2002. Combinatorial control of gene expression by nuclear receptors and coregulators. Cell. 108:465-474.

2. Moggs, J.G., and Orphanides, G. 2001. Estrogen receptors: orchestrators of pleiotropic cellular responses. EMBO Rep. 2:775-781.

3. Hall, J.M., Couse, J.F., and Korach, K.S. 2001. The multifaceted mechanisms of estradiol and estrogen receptor signaling. J. Biol. Chem. 276:36869-36872.

4. McDonnell, D.P. 1999. The molecular pharmacology of SERMs. Trends Endocrinol. Metab. 10:301-311.

5. Falkenstein, E., Tillmann, H.C., Christ, M., Feuring, M., and Wehling, M. 2000. Multiple actions of steroid hormones-a focus on rapid, nongenomic effects. Pharmacol. Rev. 52:513-556.

6. Valverde, M.A., et al. 1999. Acute activation of Maxi-K channels (hSlo) by estradiol binding to the beta subunit. Science. 285:1929-1931.

7. Pietras, R.J., and Szego, C.M. 1977. Specific binding sites for oestrogen at the outer surfaces of isolated endometrial cells. Nature. 265:69-72.

8. Simoncini, T., et al. 2000. Interaction of oestrogen receptor with the regulatory subunit of phosphatidylinositol-3-OH kinase. Nature. 407:538-541.

9. Chang, L., and Karin, M. 2001. Mammalian MAP kinase signalling cascades. Nature. 410:37-40.

10. Kousteni, S., et al. 2001. Nongenotropic, sex-nonspecific signaling through the estrogen or androgen receptors: dissociation from transcriptional activity. Cell. 104:719-730.

11. Kousteni, S., et al. 2002. Reversal of bone loss in mice by nongenotropic signaling of sex steroids. Science. 298:843-846.

12. Sun, J., et al. 1999. Novel ligands that function as selective estrogens or antiestrogens for estrogen receptor- $\alpha$ or estrogen receptor- $\beta$. Endocrinology. 140:800-804

13. Stauffer, S.R., et al. 2000. Pyrazole ligands: structure-affinity/activity relationships and estrogen receptor-alpha-selective agonists. J. Med. Chem. 43:4934-4947.

14. Jilka, R.L., Weinstein, R.S., Bellido, T., Parfitt, A.M., and Manolagas, S.C. 1998. Osteoblast programmed cell death (apoptosis): modulation by growth factors and cytokines. J. Bone Miner. Res. 13:793-802.

15. Kato, Y., Windle, J.J., Koop, B.A., Mundy, G.R., and Bonewald, L.F. 1997. Establishment of an osteocyte-like cell line, MLO-Y4. J. Bone Miner. Res. 12:2014-2023.

16. Lecka-Czernik, B., et al. 1999. Inhibition of Osf2/Cbfa1 expression and terminal osteoblast differentiation by PPARgamma2. J. Cell Biochem. 74:357-371.

17. Pottratz, S.T., Bellido, T., Mocharla, H., Crabb, D., and Manolagas, S.C. 1994. $17 \beta$-estradiol inhibits expression of human interleukin-6 promoter-reporter constructs by a receptor-dependent mechanism. J. Clin. Invest. 93:944-950.

18. Weinstein, R.S., et al. 2002. Promotion of osteoclast survival and antagonism of bisphosphonate-induced osteoclast apoptosis by glucocorticoids. J. Clin. Invest. 109:1041-1048. doi:10.1172/JCI200214538.

19. Duan, R., Xie, W., Burghardt, R.C., and Safe, S. 2001. Estrogen receptormediated activation of the serum response element in MCF-7 cells through MAPK-dependent phosphorylation of Elk-1. J. Biol. Chem. 276:11590-11598.

20. Tian, J., and Karin, M. 1999. Stimulation of Elk1 transcriptional activity by mitogen-activated protein kinases is negatively regulated by protein phosphatase 2B (calcineurin). J. Biol. Chem. 274:15173-15180.

21. Zhang, Z., Baron, R., and Horne, W.C. 2000. Integrin engagement, the actin cytoskeleton, and c-Src are required for the induction by calcitonin of the tyrosine phosphorylation of paxillin and HEF1, but not for calcitonin-induced ERK1/2 phosphorylation. J. Biol. Chem. 275:37219-37223.

22. Walk, S.F., March, M.E., and Ravichandran, K.S. 1998. Roles of Lck, Syk and ZAP-70 tyrosine kinases in TCR-mediated phosphorylation of the adapter protein Shc. Eur. J. Immunol. 28:2265-2275.

23. Mansour, S.J., et al. 1994. Transformation of mammalian cells by constitutively active MAP kinase kinase. Science. 265:966-970.

24. Whitmarsh, A.J., Shore, P., Sharrocks, A.D., and Davis, R.J. 1995. Integration of MAP kinase signal transduction pathways at the serum response element. Science. 269:403-407.

25. Datta, S.R., et al. 1997. Akt phosphorylation of BAD couples survival signals to the cell-intrinsic death machinery. Cell. 91:231-241.

26. Zhou, X.M., Liu, Y., Payne, G., Lutz, R.J., and Chittenden, T. 2000. Growth factors inactivate the cell death promoter BAD by phosphorylation of its BH3 domain on Ser155. J. Biol. Chem. 275:25046-25051.

27. Ahlbom, E., Grandison, L., Bonfoco, E., Zhivotovsky, B., and Ceccatelli, S. 1999. Androgen treatment of neonatal rats decreases susceptibility of cerebellar granule neurons to oxidative stress in vitro. Eur. J. Neurosci. 11:1285-1291.

28. Brown, P.H., Chen, T.K., and Birrer, M.J. 1994. Mechanism of action of a dominant-negative mutant of c-Jun. Oncogene. 9:791-799.

29. Kalderon, D., Roberts, B.L., Richardson, W.D., and Smith, A.E. 1984. A short amino acid sequence able to specify nuclear location. Cell. 39:499-509.

30. Rubinfeld, H., Hanoch, T., and Seger, R. 1999. Identification of a cytoplasmic-retention sequence in ERK2. J. Biol. Chem. 274:30349-30352.

31. Hill, C.S., and Treisman, R. 1995. Transcriptional regulation by extracellular signals: Mechanisms and specificity. Cell. 80:199-211.

32. Treisman, R. 1996. Regulation of transcription by MAP kinase cascades. Curr. Opin. Cell Biol. 8:205-215.

33. Minden, A., et al. 1994. Differential activation of ERK and JNK mitogenactivated protein kinases by Raf-1 and MEKK. Science. 266:1719-1723.

34. Paumelle, R., et al. 2000. Sequential activation of ERK and repression of JNK by scatter factor/hepatocyte growth factor in Madin-Darby canine kidney epithelial cells. Mol. Biol. Cell. 11:3751-3763.

35. Su, B., and Karin, M. 1996. Mitogen-activated protein kinase cascades and regulation of gene expression. Curr. Opin. Immunol. 8:402-411.

36. Cruzalegui, F.H., Cano, E., and Treisman, R. 1999. ERK activation induces phosphorylation of Elk-1 at multiple S/T-P motifs to high stoichiometry. Oncogene. 18:7948-7957.

37. Bonni, A., et al. 1999. Cell survival promoted by the Ras-MAPK signaling pathway by transcription-dependent and -independent mechanisms. Science. 286:1358-1362.

38. Buck, M., Poli, V., van der Geer, G.P., Chojkier, M., and Hunter, T. 1999. Phosphorylation of rat serine 105 or mouse threonine 217 in C/EBP beta is required for hepatocyte proliferation induced by TGF alpha. Mol. Cell. 4:1087-1092. 
39. Marais, R., Wynne, J., and Treisman, R. 1993. The SRF accessory protein Elk-1 contains a growth factor-regulated transcriptional activation domain. Cell. 73:381-393.

40. de Jager, T., et al. 2001. Mechanisms of estrogen receptor action in the myocardium. Rapid gene activation via the ERK1/2 pathway and serum response elements. J. Biol. Chem. 276:27873-27880.

41. Song, R.X., et al. 2002. Linkage of rapid estrogen action to MAPK activation by ERalpha-Shc association and Shc pathway activation. Mol. Endocrinol. 16:116-127.

42. Scheid, M.P., and Duronio, V. 1998. Dissociation of cytokine-induced phosphorylation of Bad and activation of PKB/akt: involvement of MEK upstream of Bad phosphorylation. Proc. Natl. Acad. Sci. U. S. A 95:7439-7444

43. Yang, E., et al. 1995. Bad, a heterodimeric partner for Bcl-XL and Bcl-2, displaces Bax and promotes cell death. Cell. 80:285-291.

44. Scheid, M.P., Schubert, K.M., and Duronio, V. 1999. Regulation of bad phosphorylation and association with $\mathrm{Bcl}-\mathrm{x}(\mathrm{L})$ by the MAPK/Erk kinase. J. Biol. Chem. 274:31108-31113.

45. Peruzzi, F., et al. 1999. Multiple signaling pathways of the insulin-like growth factor 1 receptor in protection from apoptosis. Mol. Cell. Biol. 19:7203-7215.

46. Lizcano, J.M., Morrice, N., and Cohen, P. 2000. Regulation of BAD by cAMP-dependent protein kinase is mediated via phosphorylation of a novel site, Ser155. Biochem. J. 349:547-557.

47. Datta, S.R., Brunet, A., and Greenberg, M.E. 1999. Cellular survival: a play in three Akts. Genes Dev. 13:2905-2927.

48. Bryant, H.U., Glasebrook, A.L., Yang, N.N., and Sato, M. 1999. An estrogen receptor basis for raloxifene action in bone. J. Steroid Biochem. Mol. Biol. 69:37-44.

49. Erlandsson, M.C., Jonsson, C.A., Lindberg, M.K., Ohlsson, C., and Carlsten, H. 2002. Raloxifene- and estradiol-mediated effects on uterus, bone and B lymphocytes in mice. J. Endocrinol. 175:319-327.

50. Black, L.J., et al. 1994. Raloxifene (LY139481 HCl) prevents bone loss and reduces serum cholesterol without causing uterine hypertrophy in ovariectomized rats. J. Clin. Invest. 93:63-69.

51. Evans, G., Bryant, H.U., Magee, D., Sato, M., and Turner, R.T. 1994. The effects of raloxifene on tibia histomorphometry in ovariectomized rats. Endocrinology. 134:2283-2288.

52. Frolik, C.A., Bryant, H.U., Black, E.C., Magee, D.E., and Chandrasekhar, S. 1996. Time-dependent changes in biochemical bone markers and serum cholesterol in ovariectomized rats: effects of raloxifene $\mathrm{HCl}$, tamoxifen, estrogen, and alendronate. Bone. 18:621-627.

53. Sato, M., Kim, J., Short, L.L., Slemenda, C.W., and Bryant, H.U. 1995. Longitudinal and cross-sectional analysis of raloxifene effects on tibiae from ovariectomized aged rats. J. Pharmacol. Exp. Ther. 272:1252-1259.

54. 1996. Random House Unabridged Dictionary. 2nd edition. S.B. Flexner and L.C. Hauck, editors. Random House. New York, New York, USA. 2027 pp.

55. Chen, J.-R., et al. 2002. Interchangeable ligand/receptor interactions mediate ERK activation and the pro- and anti- apoptotic effects of estrogens and androgens on murine osteoclasts and osteoblasts from females and males: a molecular explanation of the in vivo equivalence of their skeletal actions in either sex. J. Bone Miner. Res. 17:S133. (Abstr.)

56. Kushner, P.J., et al. 2000. Estrogen receptor pathways to AP-1. J. Steroid Biochem. Mol. Biol. 74:311-317.

57. Boyden, L.M., et al. 2002. High bone density due to a mutation in LDLreceptor-related protein 5. N. Engl. J. Med. 346:1513-1521.

58. Grotewold, L., and Rüther, U. 2002. The Wnt antagonist Dickkopf-1 is regulated by Bmp signaling and c-Jun and modulates programmed cell death. EMBO J. 21:966-975

59. Manolagas, S.C., and Kousteni, S. 2001. Non-reproductive sites of action of reproductive hormones. Endocrinology. 142:2200-2204

60. Khosla, S., et al. 1998. Relationship of serum sex steroid levels and bone turnover markers with bone mineral density in men and women: A key role for bioavailable estrogen. J. Clin. Endocrin. Metab. 83:2266-2274.

61. Bilezikian, J.P., Morishima, A., Bell, J., and Grumbach, M.M. 1998. Increased bone mass as a result of estrogen therapy in a man with aromatase deficiency. N. Engl. J. Med. 339:599-603.

62. Hodgin, J.B., et al. 2001. Estrogen receptor a is a major mediator of $17 \mathrm{~b}$ estradiol's atheroprotective effects on lesion size in Apoe ${ }^{-/-}$mice. J. Clin. Invest. 107:333-340

63. Hodgin, J.B., Knowles, J.W., Kim, H.S., Smithies, O., and Maeda, N. 2002 Interactions between endothelial nitric oxide synthase and sex hormones in vascular protection in mice. J. Clin. Invest. 109:541-548. doi:10.1172/JCI20214066

64. Croniger, C.M., et al. 2001. Mice with a deletion in the gene for CCAAT/enhancer-binding protein beta have an attenuated response to cAMP and impaired carbohydrate metabolism. J. Biol. Chem. 276:629-638.

65. Lewis, D.A., Bracamonte, M.P., Rud, K.S., and Miller, V.M. 2001. Selected contribution: effects of sex and ovariectomy on responses to platelets in porcine femoral veins. J. Appl. Physiol. 91:2823-2830.

66. Vanderschueren, D., Boonen, S., and Bouillon, R. 1998. Action of androgens versus estrogens in male skeletal homeostasis. Bone. 23:391-394.

67. Manolagas, S.C., Kousteni, S., and Jilka, R.L. 2002. Sex steroids and bone. Recent Prog. Horm. Res. 57:385-409.

68. Komesaroff, P.A., et al. 2001. Low-dose estrogen supplementation improves vascular function in hypogonadal men. Hypertension. 38:1011-1016

69. Dupont, S., et al. 2000. Effect of single and compound knockouts of estrogen receptors alpha (ERalpha) and beta (ERbeta) on mouse reproductive phenotypes. Development. 127:4277-4291.

70. Gentile, M.A., Zhang, H., Harada, S., Rodan, G.A., and Kimmel, D.B 2001. Bone response to estrogen replacement in ovx double estrogen receptor- $(\alpha$ and $\beta)$ knockout mice. J. Bone Miner. Res. 16:S146. (Abstr.)

71. Lindberg, M.K., et al. 2002. Estrogen receptor specificity for the effects of estrogen in ovariectomized mice. J. Endocrinol. 174:167-178.

72. Sims, N.A., et al. 2003. A functional androgen receptor is not sufficient to allow estradiol to protect bone after gonadectomy in estradiol receptor-deficient mice. J. Clin. Invest. 111:1319-1327. doi:10.1172/ JCI200317246

73. Vandenput, L., et al. 2001 Testosterone prevents orchidectomy-induced bone loss in estrogen receptor- $\alpha$ knockout mice. Biochem. Biophys. Res. Commun. 285:70-76.

74. Smith, E.P., et al. 1994. Estrogen resistance caused by a mutation in the estrogen-receptor gene in a man. N. Engl. J. Med. 331:1056-1061.

75. Bjarnason, N.H., et al. 2001. Six and twelve month changes in bone turnover are related to reduction in vertebral fracture risk during 3 years of raloxifene treatment in postmenopausal osteoporosis. Osteoporos. Int. 12:922-930.

76. Kousteni, S., et al. 2001. Nongenotropic activation of MAP kinases and prevention of apoptosis by SERMs in osteoblasts/osteocytes: a property shared by hydroxytamoxifene and idoxifene, but not raloxifene. J. Bone Miner. Res. 16:S415. (Abstr.)

77. Doran, P.M., Riggs, B.L., Atkinson, E.J., and Khosla, S. 2001. Effects of raloxifene, a selective estrogen receptor modulator, on bone turnover markers and serum sex steroid and lipid levels in elderly men. J. Bone Miner. Res. 16:2118-2125.

78. Ott, S.M., Oleksik, A., Lu, Y., Harper, K., and Lips, P. 2002. Bone histomorphometric and biochemical marker results of a 2-year placebo-controlled trial of raloxifene in postmenopausal women. J. Bone Miner. Res. 17:341-348. 